\title{
GEOLOGICAL AND PETROPHYSICAL CHARACTERIZATION OF THE FERRON SANDSTONE FOR 3-D SIMULATION OF A FLUVIAL-DELTAIC RESERVOIR
}

Annual Report

October 1, 1995 - September 30, 1996

By

Thomas C. Chidsey, Jr.

May 1997

Performed Under Contract No. DE-AC22-93BC14896

Utah Geological Survey

Salt Lake City, Utah

\section{National Petroleum Technology Office U. S. DEPARTMENT OF ENERGY Tulsa, Oklahoma}




\section{DISCLAIMER}

This report was prepared as an account of work sponsored by an agency of the United States Govemment. Neither the United States Govemment nor any agency thereof, nor any of their employees, makes any warranty, expressed or implied, or assumes any legal liability or responsibility for the accuracy, completeness, or usefulness of any information, apparatus, product, or process disclosed, or represents that its use would not infringe privately owned rights. Reference herein to any specific commercial product, process, or service by trade name, trademark, manufacturer, or otherwise does not necessarily constitute or imply its endorsement, recommendation, or favoring by the United States Government or any agency thereof. The views and opinions of authors expressed herein do not necessarily state or reflect those of the United States Government.

This report has been reproduced directly from the best available copy.

Available to DOE and DOE contractors from the Office of Scientific and Technical Information, P.O. Box 62, Oak Ridge, TN 37831; prices available from (615) 5768401 .

Available to the public from the National Technical Information Service, U.S. Department of Commerce, 5285 Port Royal Rd., Springfield VA 22161 


\section{DISCLAIMER}

Portions of this document may be illegible in electronic image products. Images are produced from the best available original document. 
Geological And Petrophysical Characterization Of The Ferron Sandstone For 3-D Simulation Of A Fluvial-Deltaic Reservoir

\author{
Annual Report
}

\author{
By \\ Thomas C. Chidsey, Jr.
}

May 1997

Work Performed Under Contract No. DE-AC22-93BC14896

Prepared for
BDM-Oklahomal

U.S. Department of Energy

Assistant Secretary for Fossil Energy

Robert Lemmon, Project Manager

National Petroleum Technology Office

P.O. Box 3628

Tulsa, OK 74101

Prepared by:

Utah Geological Survey

1594 West North Temple, Suite 3110

Box 146100

Salt Lake City, UT $84114-6100$ 


\section{CONTENTS}

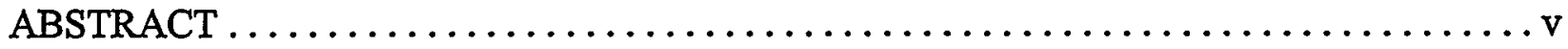

EXECUTIVE SUMMARY $\ldots \ldots \ldots \ldots \ldots \ldots \ldots \ldots \ldots \ldots \ldots \ldots \ldots \ldots \ldots \ldots$

ACKNOWLEDGMENTS $\ldots \ldots \ldots \ldots \ldots \ldots \ldots \ldots \ldots \ldots \ldots \ldots \ldots \ldots \ldots \ldots \ldots$

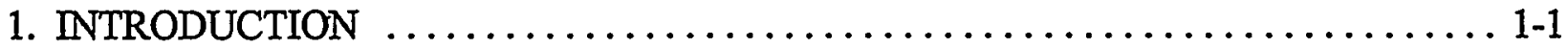

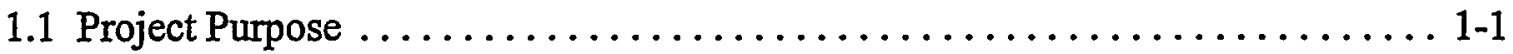

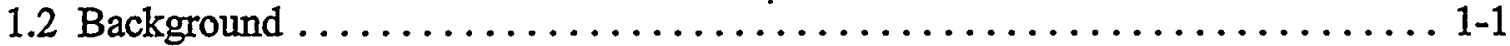

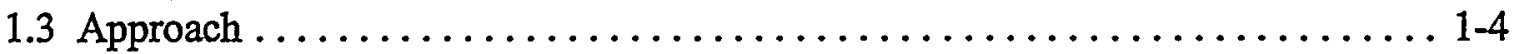

1.4 References .................................

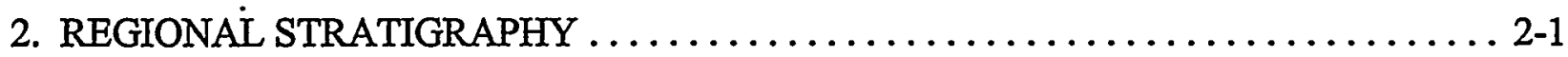

2.1 Surface Mapping/Interpretation of the Outcrop Belt ............. 2-1

2.1 .1 Methods ...................................... 2-1

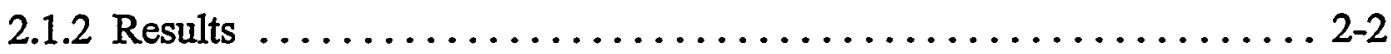

2.2 Preliminary Regional Stratigraphic Interpretations $\ldots \ldots \ldots \ldots \ldots \ldots \ldots . \ldots \ldots$

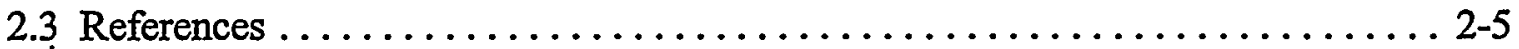

3. CASE STUDIES . . . . . . . . . . . . . . . . . . . . . . . . $3-1$

3.1 Ivie Creek Case-Study Area . . . . . . . . . . . . . . . . . .

3.1.1 Drill-Hole Core Description . . . . . . . . . . . . . . . 3-2

3.1.2 Lithofacies and Paleogeographic Interpretations $\ldots \ldots \ldots \ldots \ldots . . . .3$

3.1.2.1 Methods .......................... 3

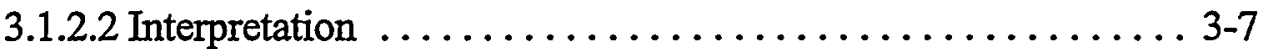

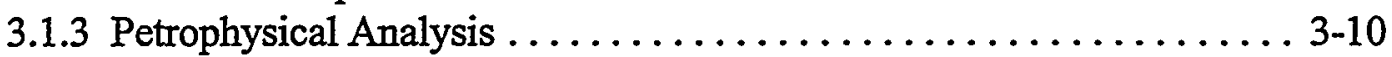

3.1.3.1 Methods ....................... 3-10

3.1.3.2 Results ........................ 3-10

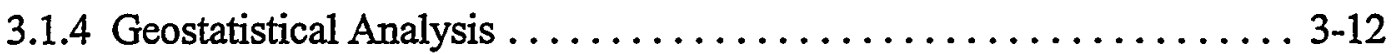

3.1.4.1 Methods . ......................... $3-12$

3.1.4.2 Results ............................ 3-13

3.2 Willow Springs Wash Case-Study Area $\ldots \ldots \ldots \ldots \ldots \ldots \ldots \ldots \ldots \ldots$ 3-17

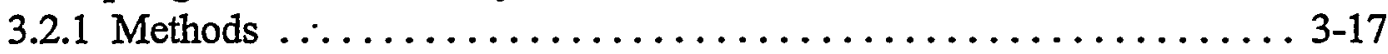

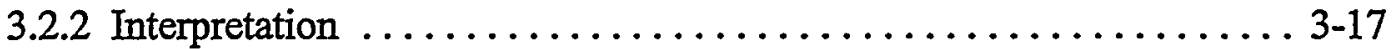

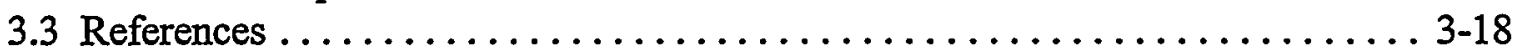

4. RESERVOIR MODELING $\ldots \ldots \ldots \ldots \ldots \ldots \ldots \ldots \ldots \ldots \ldots \ldots \ldots \ldots, 4,1$

4.1 Overall Modeling Strategy $\ldots \ldots \ldots \ldots \ldots \ldots \ldots \ldots \ldots \ldots \ldots \ldots, 4-1$

4.1.1 Task I - Two-Dimensional Detailed-Scale Simulations . . . . . . . . . 4-1

4.1.2 Task II - Two-Dimensional Intermediate-Scale Simulations . . . . . . 4-4 


\subsubsection{Task III - Three-Dimensional Reservoir Characterization and}

Simulation .............................. 4 4

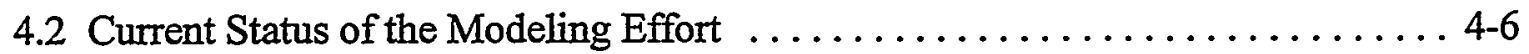

4.2.1 Two-Dimensional Simulations (Tasks I and II) $\ldots \ldots \ldots \ldots \ldots .4$

4.2.2 Three-Dimensional Simulations (Task III) .............. 4-10

4.2.3 Continuing Effort to Create Synthetic Clinoform-Like Objects . . . . 4-10

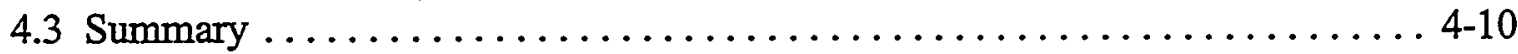

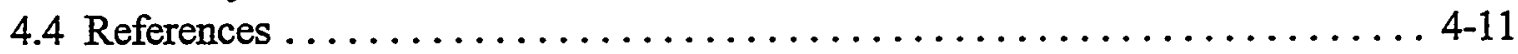

5. TECHNOLOGY TRANSFER $\ldots \ldots \ldots \ldots \ldots \ldots \ldots \ldots \ldots \ldots \ldots \ldots \ldots \ldots \ldots \ldots$ 5-1

5.1 Utah Geological Survey Petroleum News, Survey Notes,

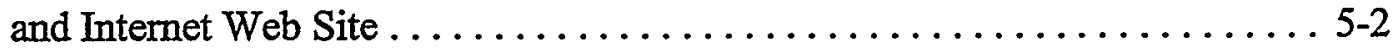

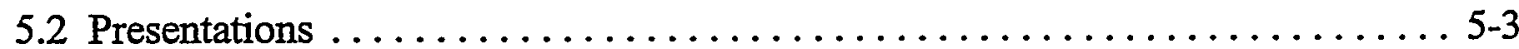

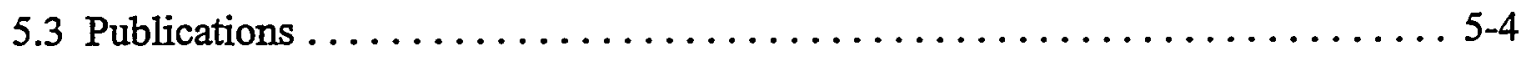




\section{FIGURES}

Figure 1.1. Location map of the Ferron Sandstone project area $\ldots \ldots \ldots \ldots \ldots \ldots \ldots \ldots .1-2$

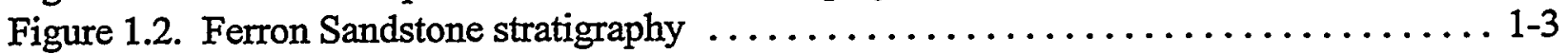

Figure 2.1. Example of an annotated photomosaic north, from Muddy Creek Canyon . . . 2 2-2

Figure 2.2. Diagram showing relative positions of Ferron parasequences and parasequence

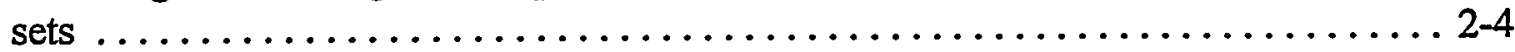

Figure 3.1. Locations of six drill holes in the Ivie Creek case-study area $\ldots \ldots \ldots \ldots \ldots .3-2$

Figure 3.2. Graphic interpretation of core, with gamma-ray curve, from the Ivie Creek

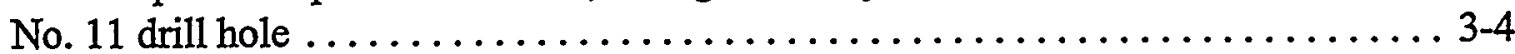

Figure 3.3. Scaled reconstruction of Ivie Creek photomosaic from scanned line work . . . . . 3-5

Figure 3.4. Schematic, discretized three-dimensional volume from the selected block of the Kf-1-Iv-a parasequence within the Ivie Creek amphitheatre. . . . . . . . . . . 3-6

Figure 3.5. Scaled cross sections of the Kf-1-Iv-a parasequence from the Ivie Creek

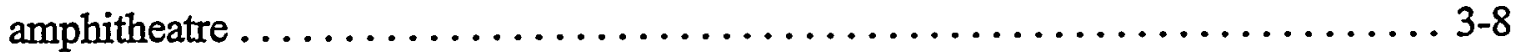

Figure 3.6. Paleogeographic interpretation of the third of five time steps of the Kf-1-Ivie Creek-a parasequence. ............................... 3-9

Figure 3.7. Comparisons of geophysical log and continuous-core measurements, for both velocity and density, at the Ivie Creek No. 3 drill hole $\ldots \ldots \ldots \ldots \ldots \ldots \ldots .11$

Figure 3.8. Cumulative percent permeability plots from the Ferron Sandstone, Ivie Creek

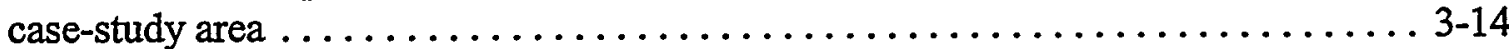

Figure 3.9. Statistical analyses of the clinoform lithofacies from the Kf-1-Ivie Creek-a

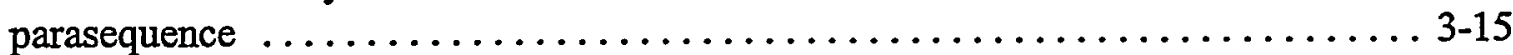

Figure 3.10. Statistical analyses of the $\mathrm{Kf}-2$ parasequence set as a whole and the three

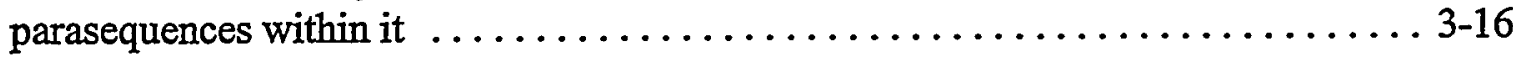

Figure 4.1. Ivie Creek case-study area including location of the two- and three-dimensional model domains to be simulated. ........................... 4-2

Figure 4.2. Sketch of an idealized clinoform geometry found at the Ivie Creek case-study area. ........................................

Figure 4.3. Sketch of detailed two-dimensional modeling domain showing a generic package of clinoforms with intervening bounding layers for a series of well

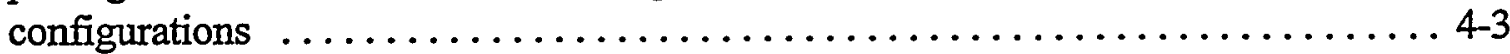

Figure 4.4. Cross section of the intermediate-scale, two-dimensional modeling domain . . . 4-5

Figure 4.5. Sketch of the three-dimensional model domain $\ldots \ldots \ldots \ldots \ldots \ldots \ldots \ldots$ 4-6

Figure 4.6. Detailed view of clinoforms mapped in the Kf-1-Iv-a parasequence at the Ivie Creek amphitheatre $\ldots \ldots \ldots \ldots \ldots \ldots \ldots \ldots \ldots \ldots \ldots \ldots \ldots \ldots \ldots .8,8$

Figure 4.7. Sample model domain showing closed polygons representing individual clinoforms and a digitized polygon set with bounding surfaces

Figure 5.1. Location of the Ferron coalbed gas "fairway", Drunkards Wash field, and drilling prospects, Carbon, Emery, Sanpete, and Sevier Counties, Utah. 


\section{ABSTRACT}

The objective of the Ferron Sandstone project is to develop a comprehensive, interdisciplinary, quantitative characterization of a fluvial-deltaic reservoir to allow realistic interwell and reservoir-scale models to be developed for improved oil-field development in similar reservoirs world-wide. Quantitative geological and petrophysical information on the Cretaceous Ferron Sandstone in east-central Utah was collected. Both new and existing data is being integrated into a three-dimensional model of spatial variations in porosity, storativity, and tensorial rock permeability at a scale appropriate for inter-well to regional-scale reservoir simulation. Simulation results could improve reservoir management through proper infill and extension drilling strategies, reduction of economic risks, increased recovery from existing oil fields, and more reliable reserve calculations. Transfer of the project results to the petroleum industry is an integral component of the project. This report covers research activities for fiscal year 1995-96, the third year of the project. Most work consisted of interpreting the large quantity of data collected over two field seasons.

The project is divided into four tasks: (1) regional stratigraphic analysis, (2) case studies, (3) reservoirs models, and (4) field-scale evaluation of exploration strategies. The primary objective of the regional stratigraphic analysis is to provide a more detailed interpretation of the stratigraphy and gross reservoir characteristics of the Ferron Sandstone as exposed in outcrop. The primary objective of the case-studies work is to develop a detailed geological and petrophysical characterization, at well-sweep scale or smaller, of the primary reservoir lithofacies typically found in a fluvialdominated deltaic reservoir. Work on tasks 3 and 4 consisted of developing two- and threedimensional reservoir models at various scales. The bulk of the work on these tasks will be conducted primarily during the last year of the project, and will incorporate the data and results of the regional stratigraphic analysis and case-studies tasks.

Regionally, the Ferron Sandstone consists of at least seven delta-front sandstone bodies or parasequence sets. Our work focuses on two parasequence sets (Kf-1 and Kf-2) in the lower part of the Ferron. The Kf-1 represents a river-dominated delta deposit which changes from proximal to distal. The Kf-2 contains more and cleaner sand, indicating a more wave-influenced environment of deposition.

During fiscal year 1995-96, photographs of the Ferron Sandstone outcrop belt within the study area were digitized and assembled into photomosaics. Lithofacies, measured sections, vertical and horizontal scales, and other data were plotted on the photomosaics in the field for both the regional and case-study analyses of two areas: Ivie Creek and Willow Springs Wash. Petrophysical and thin section analysis was conducted on core plugs from various lithofacies in both the $\mathrm{Kf}-1$ and Kf-2 sandstones. The paleogeography was mapped and the lithofacies described for each parasequence in the case-study areas.

Permeability transect locations in the Ivie Creek case-study area encompass the majority of the lithofacies present in the delta-front sequence. The transects span the proximal, middle, and distal portions of the delta-front rocks of the $\mathrm{Kf}-1$ and representative sections of the $\mathrm{Kf}-2$. Data from these transects were used to determine the statistical structure of the spatially variable permeability field within the delta front and to investigate how geological processes control the 
spatial distribution of permeability. Detailed architectural and permeability models based on the high-resolution field work were developed over the year.

Technology transfer during the third project year consisted of booth displays for various professional conventions, technical presentations, publications, and establishment of a project home page on the Internet. 


\section{EXECUTIVE SUMMARY}

Understanding reservoir heterogeneity is the key to increasing oil recovery from existing fields in the United States. Fluvial-deltaic reservoirs have the largest developed oil reserves, and due to the high degree of reservoir heterogeneity, the largest amount of untapped and unrecovered oil within developed reservoirs. Reservoir heterogeneity is dramatically exposed in the fluvial-deltaic Ferron Sandstone Member of the Cretaceous Mancos Shale in east-central Utah.

The Utah Geological Survey (UGS) leads a multidisciplinary team to develop a comprehensive and quantitative characterization of the Ferron Sandstone as an example of a fluvialdeltaic reservoir which will allow realistic interwell and reservoir-scale modeling. These models may be used for improved oil-field development in similar reservoirs world-wide. The Ferron Sandstone project team consists of the UGS (prime contractor), University of Utah, Brigham Young University, Utah State University, Amoco Production Company, Mobil Exploration and Producing Company, and several geologic contractors. This research is performed under the Geoscience/Engineering Reservoir Characterization Program of the U.S. Department of Energy, National Technology Office, Bartlesville, Oklahoma. This report covers research activities for fiscal year 1995-96, the third year of the project. Most work consisted of interpreting large quantities of data collected over two field seasons.

The project is divided into four tasks: (1) regional stratigraphic analysis, (2) case studies, (3) development of reservoirs models, and (4) field-scale evaluation of exploration strategies. The primary objective of the regional stratigraphic analysis is to provide a more detailed interpretation of the sequence stratigraphy and gross reservoir characteristics of the Ferron Sandstone as exposed in outcrop. This regional study includes determining the dimensions and depositional environment of important sandstone reservoir bodies and the nature of contacts with adjacent rocks. The primary objective of the case-studies work is to develop a detailed geological and petrophysical characterization of some of the primary reservoir lithofacies typically found in a fluvial-dominated deltaic reservoir. The bulk of the work on tasks 3 and 4, reservoir models and field-scale evaluation of exploration strategies, will be conducted primarily during the last year of the project, and will incorporate the data and results of the regional stratigraphic analysis and case-studies tasks.

Regionally, the Ferron Sandstone consists of at least seven delta-front sandstone bodies or parasequence sets. The focus of our work is two parasequence sets in the lower part of the Ferron designated as the $\mathrm{Kf}-1$ and $\mathrm{Kf}-2$. The $\mathrm{Kf}-1$ represents a river-dominated delta deposit which changes from proximal to distal. The $\mathrm{Kf}-2$ contains more and cleaner sand, indicating a more waveinfluenced environment of deposition. Recognizable sequences within the sets have been designated with a location code and lower-case letters (for example, $\mathrm{Kf}-1-\mathrm{Iv}$-a is Ferron Sandstone Ivie Creek parasequence a). In some cases, the divisions may lack transgressive surfaces, yet are recognizable by changes in sedimentary styles.

During fiscal year 1995-96, photographs of the Ferron Sandstone outcrop belt within the study area were digitized and assembled into photomosaics. Lithofacies, measured sections, vertical and horizontal scales, and other data were plotted on the photomosaics in the field for both the regional and case-study analyses. 
Field work was completed in the two case-study areas: Ivie Creek and Willow Springs Wash in the central and southern parts respectively of the study area. Lithofacies were described and paleogeographic maps constructed for each parasequence in these areas. The Ferron Sandstone in the Ivie Creek case-study area consists of two regional-scale parasequence sets, the $\mathrm{Kf}-1$ and $\mathrm{Kf}-2$. The Ivie Creek case-study area was selected since it contains abrupt facies changes in the $\mathrm{Kf}-1$ deltafront sandstones. The basal unit is a thick, sandy parasequence composed of clinoform units which pinch out to the west. This basal unit is overlain by a thin, silty parasequence which extends farther to the west. Reservoir modeling is being conducted on data collected from and geological interpretations of the $\mathrm{Kf}-1$ parasequence set in the Ivie Creek case-study area. The modeling effort is concentrating on: (1) variations in fluid flow between the lithofacies, (2) the amount of communication between each parasequence, and (3) the effects the various bounding surfaces within parasequences would have on fluid flow in these units.

The Willow Springs Wash area is the largest of the study areas and was selected for the excellent three-dimensional aspect of exposures in the Willow Springs Wash and Indian Canyon areas. The focus of the work in the Willow Springs Wash case-study area will be parasequences of the $\mathrm{Kf}-1$ delta-front. No reservoir simulations will be conducted on data collected from the Willow Springs Wash area. However, the architectural elements interpreted from the outcrops will be incorporated into the overall reservoir model for the Ferron Sandstone.

Petrophysical and thin section analysis were conducted on core plugs taken from various lithofacies in both the $\mathrm{Kf}-1$ and $\mathrm{Kf}-2$ sandstones. In thin section the samples are quartz-rich sandstones with a complex diagenetic history. Spatial variations in lithofacies, stratigraphic thickness, sedimentary structures, and permeability data were quantified through geostatistical analysis. The net footage and relative percentage of each sedimentary structure, biologic structure, average megascopic grain size, and sandstone/shale ratio were calculated for various lithofacies in the Ivie Creek case-study area.

Permeability transect locations in the Ivie Creek case-study area encompass the majority of the lithofacies present in the delta-front sequence. The transects span the proximal, middle, and distal portions of the delta-front rocks of the $\mathrm{Kf}-1$ and representative sections of the $\mathrm{Kf}-2$. Data from these transects were used to determine the statistical structure of the spatially variable permeability field within the delta front and to investigate how geological processes control the spatial distribution of permeability.

A 2,000 feet by 2,000 feet $(610 \times 610 \mathrm{~m})$ block within the Ivie Creek case-study area was used as the site from which detailed, two- and three-dimensional geological and petrophysical models developed as input to a series of reservoir simulations. Data needed for these models was be obtained by geological mapping, outcrop gamma-ray logging, petrophysical measurements on core plugs, and mini-permeameter testing of slabbed core from three Ivie Creek drill holes. The simulation study area encompasses the river-dominated lithofacies of the $\mathrm{Kf}-1$ parasequence set.

We anticipate simulating fluid flow through at least three rock volumes at two different scales. We will begin at the interwell scale with a very detailed model of the $\mathrm{Kf}-1-\mathrm{Iv}$-a clinoform features. A scaling-up procedure will be used to homogenize and transfer petrophysical information from the very detailed interwell-scale models to the reservoir scale.

Technology transfer during the third project year consisted of displaying project materials at the UGS booth during the national and regional conventions of the American Association of 
Petroleum Geologists. Eight technical and nontechnical project presentations were made to various professional organizations, government officials, and general public. Project team members published abstracts, open-file reports, guidebook articles, or newsletters detailing project progress and results. The UGS established a home page for the Ferron Sandstone project on the Internet. 


\section{ACKNOWLEDGMENTS}

This research is performed under the Geoscience/Engineering Reservoir Characterization Program of the U.S. Department of Energy (DOE), National Petroleum Technology Office, Bartlesville, Oklahoma, contract number DE-AC22-93BC14896. The Contracting Officer's Representative is Robert Lemmon.

\section{Project Contributors:}

Principal Investigator: M.L. Allison; Utah Geological Survey, Salt Lake City, UT

Program Manager: T.C. Chidsey, Jr.; Utah Geological Survey, Salt Lake City, UT

Task Contributing Scientists and Organizations:

R.L. Bon, T.C. Chidsey, Jr., Brigitte Hucka, M.D. Laine, S.N. Sommer, D.A. Sprinkel, D.E. Tabet, B.T. Tripp, K.A. Waite; Utah Geological Survey, Salt Lake City, UT

P.B. Anderson; Geologic Consultant, Salt Lake City, UT

T.A. Ryer; The ARIES Group, Louisville, CO

M.A. Chan, C.B. Forster, Richard Jarrard, Ann Mattson, S.H. Snelgrove; University of Utah, Salt Lake City, UT

J.A. Dewey, Jr., and T.H. Morris; Brigham Young University, Provo, UT

J.V. Koebbe; Utah State University, Logan, UT

Don Best, Bruce Welton, F.M. Wright III; Mobil Exploration/Producing Technical Center, Dallas, TX

R.L. Chambers, Chandra Rai, and Carl Sondergeld; Amoco Production Company, Tulsa, OK 


\section{INTRODUCTION}

Thomas C. Chidsey, Jr.; Utah Geological Survey

\subsection{Project Purpose}

Nationwide, fluvial-deltaic reservoirs have the largest developed oil reserves, and due to the high degree of reservoir heterogeneity, the largest amount of untapped and unrecovered oil within developed reservoirs. The purpose of this multi-year project is to use the Ferron Sandstone to develop a comprehensive, interdisciplinary, and quantitative characterization of an outcrop analogue to fluvial-deltaic reservoirs which will allow realistic inter-well and reservoir-scale modeling to be used for improved oil-field development in actual reservoirs world-wide. The fluvial-deltaic Ferron Sandstone Member of the Cretaceous Mancos Shale in east-central Utah (figure 1.1) is a perfect analog since its reservoir heterogeneity is dramatically exposed in outcrop. The results may benefit industry by: (1) increasing recoverable reserves by identifying untapped compartments created by reservoir heterogeneity, (2) reducing development costs by more efficiently siting infill drilling locations, (3) increasing deliverability by exploiting the reservoir along optimal fluid-flow paths, (4) enhancing the application of new technologies, such as horizontal drilling, by identifying optimal drilling directions to maximize fluid-flow, and (5) identifying reservoir trends for field extension drilling.

The geological and petrophysical properties of the Ferron Sandstone are being quantitatively determined by a multidisciplinary team. To evaluate the Ferron Sandstone as a model for fluvialdeltaic reservoirs, the UGS, University of Utah, Brigham Young University, Utah State University, Amoco Production Company, Mobil Exploration/Producing Technical Center, The ARIES Group, and geologic consultant Paul B. Anderson entered into a cooperative agreement with the U.S. Department of Energy as part of its Geoscience/Engineering Reservoir Characterization program.

Both new and existing data is being integrated into a three-dimensional representation of spatial variations in porosity, storativity, and tensorial rock permeability at a scale appropriate for inter-well to regional-scale reservoir simulation. The project is divided into four tasks: (1) regional stratigraphic analysis, (2) case studies, (3) development of reservoirs models, and (4) field-scale evaluation of exploration strategies (to be included in the Final Report). Transfer of the project results to the petroleum industry is an integral component of the project.

This report is organized into five sections: Introduction, Regional Stratigraphy, Case Studies, Reservoir Modeling, and Technology Transfer. It is a progress report of on-going research and is not intended as a final report. Whenever possible, preliminary conclusions have been drawn based on available data and field observations.

\subsection{Background}

The Ferron Sandstone Member of the Cretaceous Mancos Shale is well exposed along the west flank of the San Rafael uplift of east-central Utah (figure 1.1). The Ferron Sandstone is a fluvial-deltaic deposit with excellent exposures of a variety of delta facies along the margins of a 
rapidly subsiding basin (figure 1.2a). The Ferron Sandstone is an analogue for many of the highly productive reservoirs in the Alaskan North Slope, Gulf Coast, and Rocky Mountain regions.
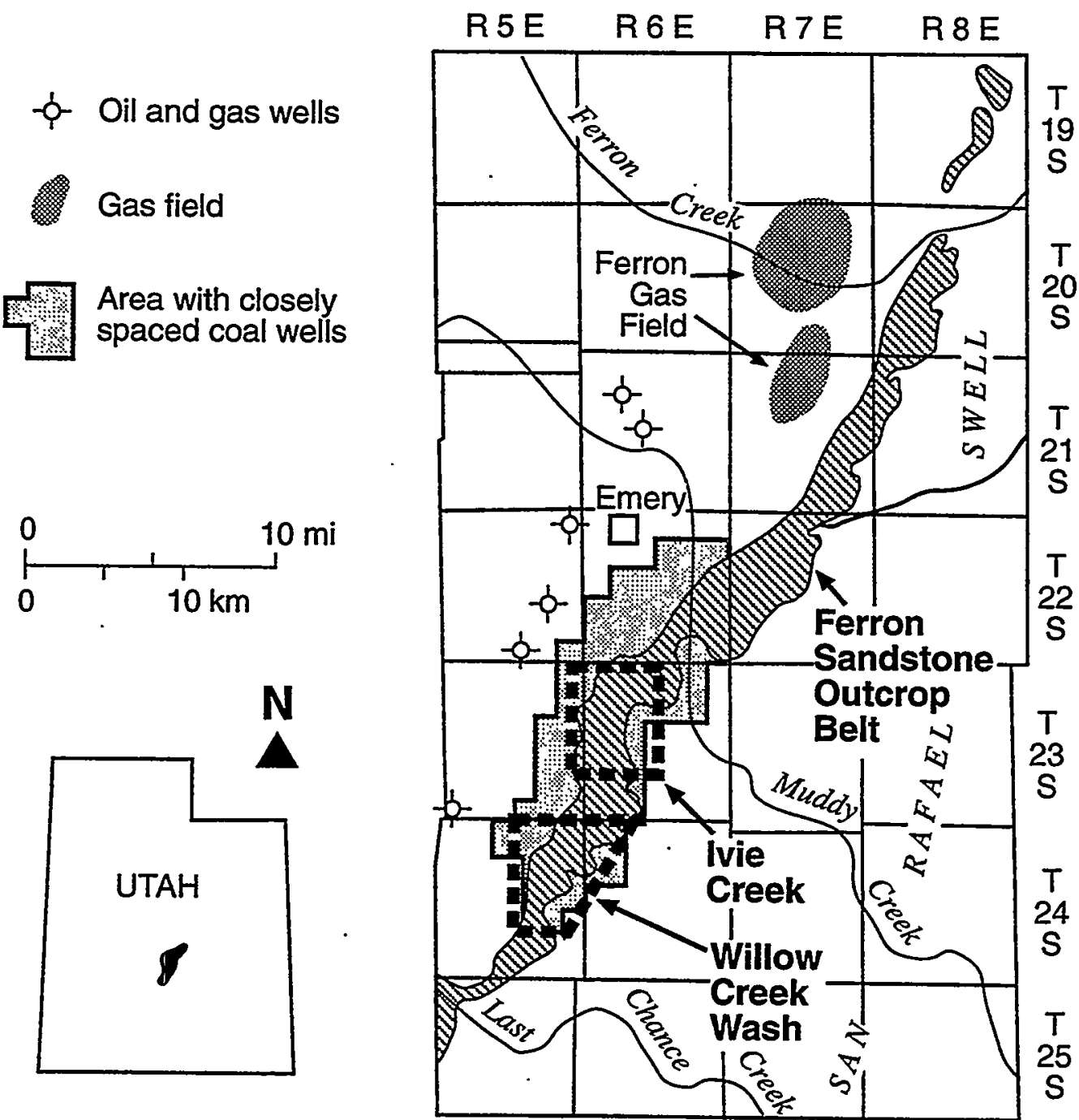

Figure 1.1. Location map of the Ferron Sandstone project area (outcrop belt is cross-hatched) showing detailed case-study areas (outlined by heavy dashed lines). 


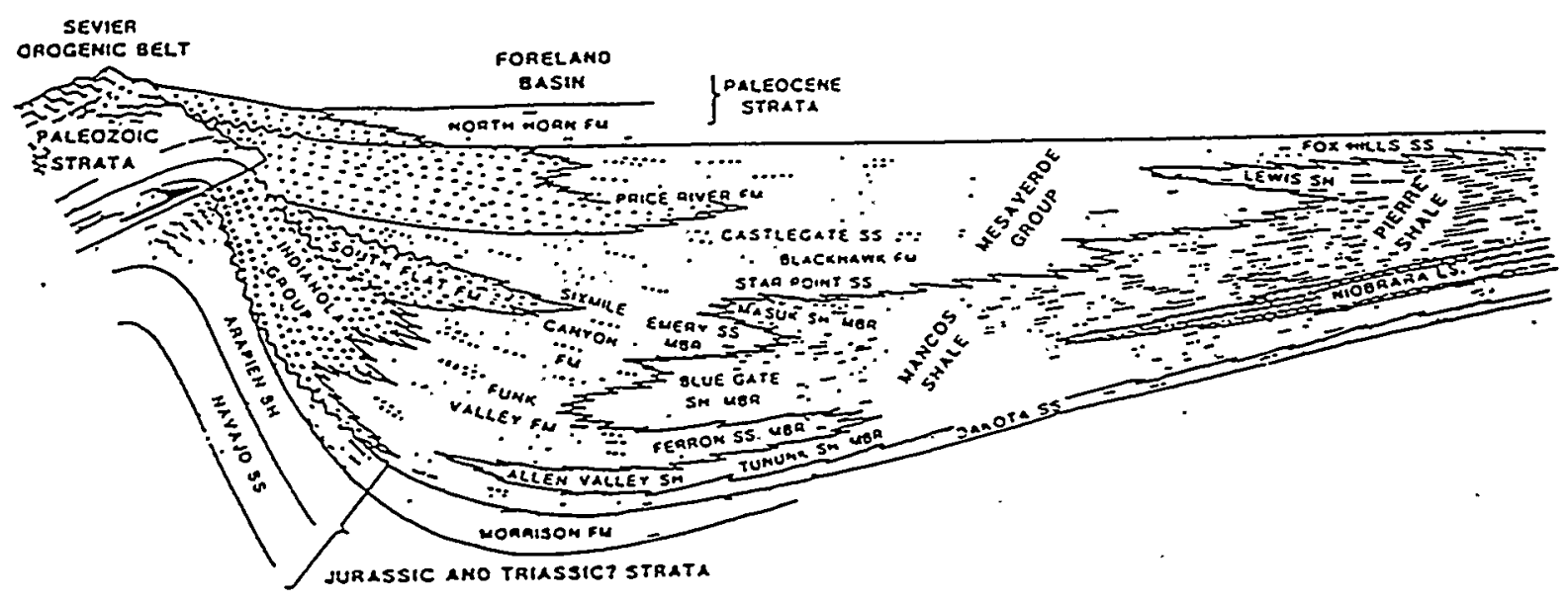

(A)

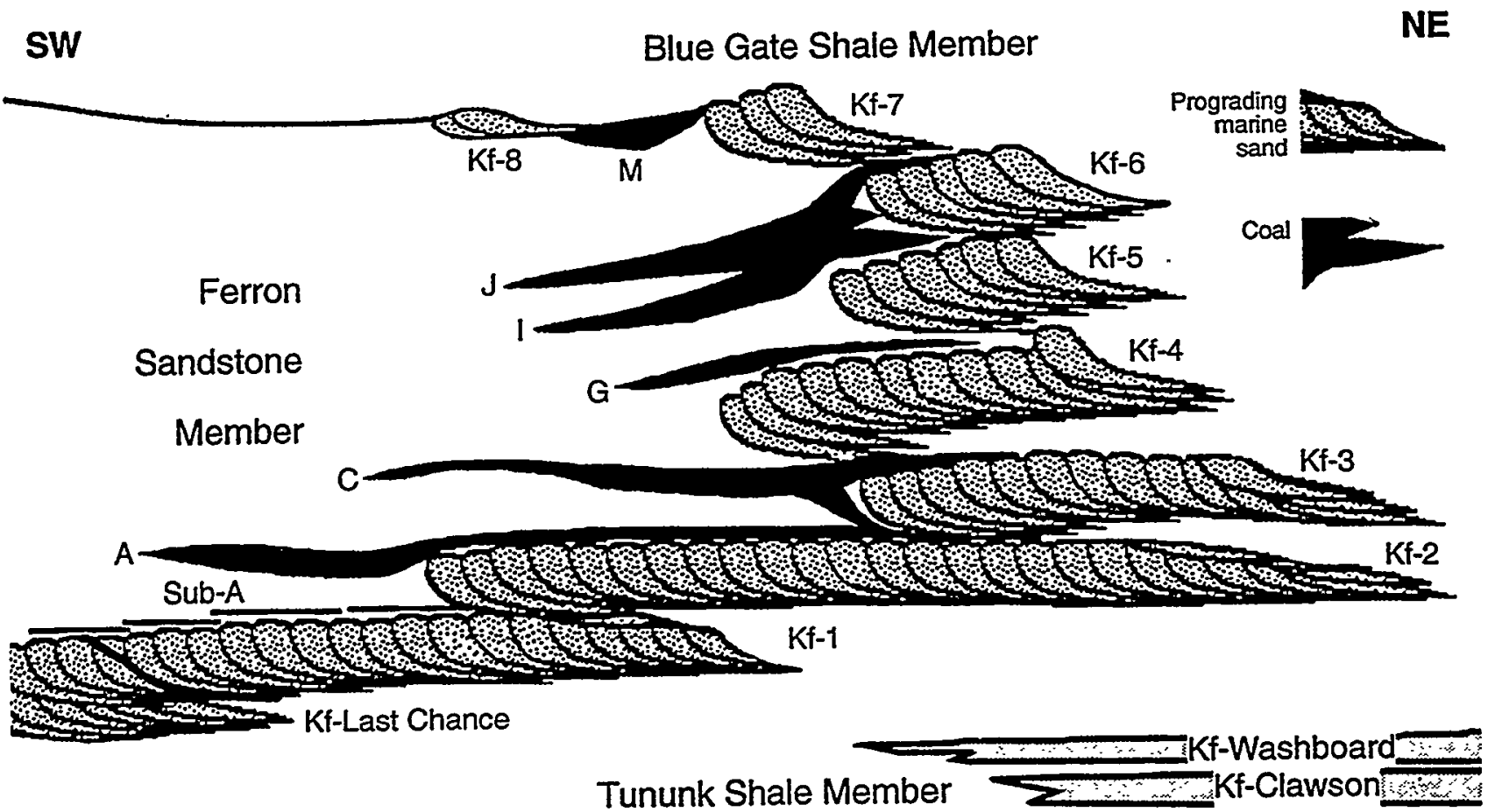

(B)

Figure 1.2. Ferron Sandstone stratigraphy: (A) cross section of the Cretaceous foreland basin across Utah (from Ryer, 1981), and (B) diagrammatic cross section of the Ferron Sandstone and adjacent members of the Mancos Shale showing the numbering and stacking of the deltaic parasequence sets (modified from Ryer, 1991). Coal horizons (black) are designated by letters. 
The Ferron Sandstone is an eastward-thinning clastic wedge deposited during Upper Cretaceous time. The Ferron and equivalent portions of the Frontier Formation in northern Utah and Wyoming record a pronounced and widespread regression of the Cretaceous Western Interior seaway. In the study area, these deposits accumulated on a deltaic shoreline in a rapidly subsiding portion of the Cretaceous foreland basin. The Ferron consists of a series of stacked, transgressiveregressive cycles (parasequence sets) which are well displayed in outcrop. Nine parasequence sets, the Last Chance set and the rest numbered $\mathrm{Kf}-1$ through $\mathrm{Kf}-8$ in ascending order have been mapped (figure 1.2b). These various parasequence sets define a hierarchical pattern of (1) seaward-stepping, (2) vertically-stacked, and (3) landward-stepping depositional geometries. This architecture indicates an initial strong supply of sediment relative to available space where sediment could accumulate, followed by near-balance, and then a relative decrease in sediment supply. Each parasequence set contains in outcrop all, or portions of each of the complex lithofacies that make up a typical fluvial-dominated deltaic deposit. Such lithofacies include meander channels, distributary channels, tidal channels, mouth-bar complexes, wave-modified strandlines, bar-finger sandstones, prodelta and delta-front deposits, transgressive sandstones, as well as bayfill, lagoonal, and floodplain deposits.

The excellent exposures and accessibility of the three-tiered, hierarchical stacking pattern and associated complex lithofacies of the nine parasequence sets make the Ferron Sandstone of Utah the best analogue for petroleum reservoirs in fluvial-dominated deltas throughout the world. The Ferron Sandstone is a good analogue for the Triassic Ivishak Formation (the principal reservoir at Prudhoe Bay field, Alaska) and for the Tertiary Wilcox and Frio Formations of south Texas. The Ferron Sandstone is also an excellent model for and is correlative to, the Cretaceous Frontier Formation which produces petroleum throughout Wyoming. The Ferron lithofacies are also a good analogue for the Tertiary Green River and Wasatch Formations, the major oil and gas producing reservoirs in the Uinta Basin, Utah. In addition to its value as a reservoir analogue, sands and coalbeds of the Ferron Sandstone produce gas north of the study area in the Wasatch Plateau and along the west-northwest flank of the San Rafael uplift, currently the most active gas play in Utah.

This project addresses the need for reservoir engineers to deal with complex reservoir heterogeneities on an interwell to field scale. These scales are difficult to resolve in reservoir exploration and development activities. Standard industry approaches to field development rely on generic depositional models constrained primarily by data obtained in petrophysical (logging and coring) evaluations of exploration and development wells. The quantity, quality, and distribution of these data are typically insufficient to adequately model the reservoir. Work on the Ferron Sandstone is predicated on the assumption that detailed outcrop mapping of petrophysical and geological properties of this analogue reservoir will provide a comprehensive database and accurate reservoir simulation. Simulation results can be used to guide exploration and development strategies in reservoirs found in similar depositional environments.

\subsection{Approach}

The primary approach of the study is to quantitatively determine geological and petrophysical properties of the Ferron Sandstone. This information should help to improve reserve estimates in fluvial-dominated deltaic reservoir systems and aid in designing more efficient production strategies. To reach this goal, existing and new data have been collected for integration into a three-dimensional 
representation of spatial variations in porosity, storativity, and tensorial character of rock permeability at a scale appropriate for interwell-to regional-scale reservoir simulation.

During the 1995-96 project year (the third year of the project), regional facies mapping was completed to refine current models for the architecture, geometry, and distribution of lithofacies in the Ferron Sandstone. Case-study areas provided more detailed mapping and analysis of specific lithofacies important to reservoir production (figure 1.1). Extensive vertical and lateral outcrops offered excellent opportunity for investigation. The existing database was augmented with additional detailed mapping of the three-dimensional geologic structure and determination of petrophysical properties of various lithofacies at case-study locations within the Ferron Sandstone outcrop belt to serve as reservoir analogues. Determining permeability anisotropy within each facies was an important consideration and was accomplished by mapping lithofacies, grain sizes, and sedimentary structures.

Collected information is being used to identify flow units within each case-study area at the scale of a single production well. Numerical simulations of reservoir response were used to assess the scale at which flow units must be defined within each lithofacies. Appropriate scales were established from which three-dimensional gridded databases are being developed that contain the best estimates of the three-dimensional distributions of both scalar (porosity and storativity) and tensorial (permeability) petrophysical properties of flow units found within the various lithofacies of the Ferron Sandstone. Architectural heterogeneities (such as texture and diagenesis) were examined in thin sections and are being compared to flow units. Standard geostatistical approaches are being used to extrapolate between the detailed study areas and other observation points.

Reservoir modeling at the field scale will be performed to evaluate how a detailed understanding of the geological and petrophysical structure of the Ferron Sandstone will enhance exploration and development strategies in similar reservoir systems. Numerical simulations of reservoir response to multiple-well production strategies will be used to quantitatively assess the effectiveness of both standard and modified strategies.

\subsection{References}

Ryer, T.A., 1981, Deltaic coals of Ferron Sandstone Member of Mancos Shale: predictive model for Cretaceous coal-bearing strata of Western Interior: American Association of Petroleum Geologists Bulletin, v. 65, no. 11, p. 2323-2340.

---1991, Stratigraphy, facies, and depositional history of the Ferron Sandstone in the canyon of Muddy Creek, east-central Utah: in Chidsey, T.C., Jr., editor, Geology of east-central Utah: Utah Geological Association Publication 19, p. 45-54. 


\title{
2. REGIONAL STRATIGRAPHY
}

\author{
Thomas A. Ryer; The ARIES Group \\ Paul B. Anderson; Geological Consultant \\ and \\ Thomas C. Chidsey, Jr.; Utah Geological Survey
}

The regional stratigraphy of the Ferron Sandstone has been described by Anderson (1991), Barton and Tyler (1991), Cotter (1971, 1975a, 1975b, 1976), Davis (1954), Gardner (1991), Hodder and Jewell (1979), and Ryer (1981a, 1981b, 1982a, 1982b, 1983, 1991). The primary objective of additional study of regional stratigraphy is to provide a more detailed interpretation of the stratigraphy of the Ferron Sandstone outcrop belt from Last Chance Creek to Ferron Creek (figure 1.1). This area is similar in scale to a moderate to large oil reservoir. The regional study includes determining the dimensions and depositional environment of each sandstone body, and the nature of the contacts with adjacent rocks or flow units. The regional study provides a basis for selecting prime outcrops for detailed case studies of the major reservoir types (mouth-bar complex, wavemodified and river-dominated delta front, distributary channel, and tidal channels). Toward the end of the project, the regional morphological framework will be incorporated into model simulations at the oil and gas field scale.

\subsection{Surface Mapping/Interpretation of the Outcrop Belt}

The main Ferron Sandstone cliff and its deeply incised canyons together provide a threedimensional view of lithofacies variations and transitions. The Ferron Sandstone has excellent exposures along strike; numerous canyons that cut perpendicular to strike offer excellent exposures along the depositional dip direction. Most of the near-vertical outcrop belt within the study area was obliquely photographed during the 1994 field season. Outcrop images were digitized to develop a computer graphics database for interpretation and manipulation. Important bounding surfaces, geometries, and depositional environments are being mapped in the field on photomosaics to characterize the variability of fluvial-dominated deltaic reservoirs.

\subsubsection{Methods}

Reproducible black-and-white prints were generated from digitized oblique outcrop photographs using image-editing software and laser printers. Photomosaics were constructed from the images with distortions digitally removed. Scale of the photos was determined in the field by measuring between locatable points on the photograph and those same points on the ground. During field mapping, coverage of each photomosaic was plotted on a 7.5-minute topographic quadrangle map with the aid of aerial photos.

The photomosaics were annotated with parasequences, parasequence sets, and lithofacies boundaries. Parasequence sets generally correlate to the existing stratigraphy of the nine delta-front sandstones or genetic sequences. Parasequences names were based on case-study locations and were assigned an A-, B-, C-, D-type nomenclature, which allowed for adding parasequences identified later without disrupting the entire numbering system. 


\subsubsection{Results}

The UGS combined digitized land-based and aerial photographs of the Ferron Sandstone outcrop belt into 138 photomosaics using image-editing software. These photomosaics cover 80 miles $(160 \mathrm{~km}$ ) of Ferron Sandstone outcrop (figure 1.1). Photomosaic interpretation first incorporated observations from the 1995 field season. Each photomosaic is being annotated with following information: flooding surfaces (transgressive surfaces of erosion), possible parasequence boundaries (surfaces which may be a flooding surface, but for which there is not clear evidence of transgression), bases of channels, depositional tops of shoreline and bay-fill units, significant bedding surfaces of shoreline units, lateral accretion in tidal inlet and fluvial channel deposits, and bedding surfaces in slump features (figure 2.1). A scale bar is included on the photomosaics based

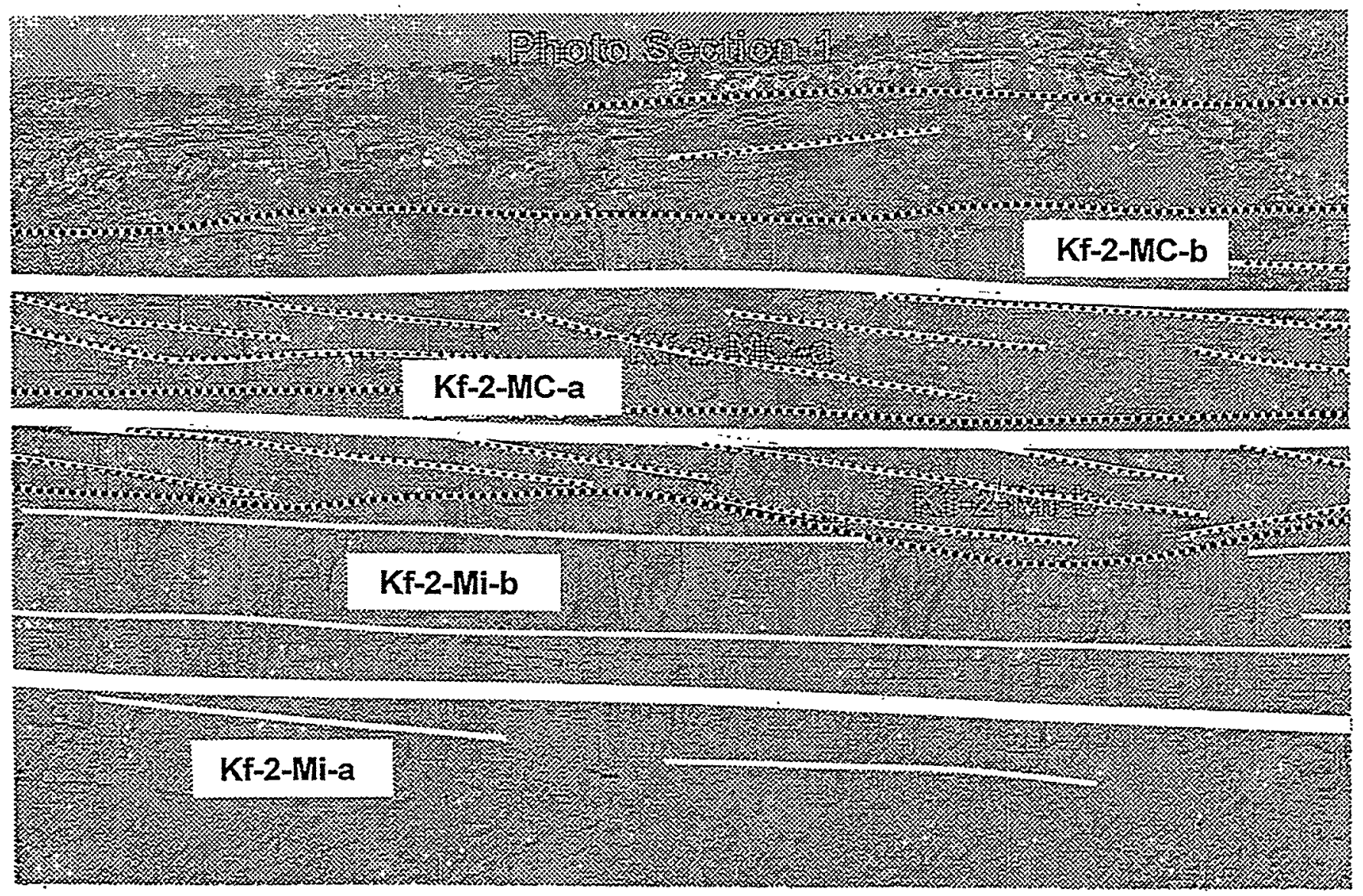

Figure 2.1. Example of an annotated photomosaic, oriented south to north, from Muddy Creek Canyon (T. 22 S., R. 06 E., Salt Lake Base Line, Emery County) for regional stratigraphic interpretation of the $\mathrm{Kf}-2-\mathrm{Miller}$ Canyon (Kf-2-Mi) a and $\mathrm{b}$ parasequences and the $\mathrm{Kf-2}$ Muddy Creek (Kf-2-MC) a and $b$ parasequences of the Ferron Sandstone $\mathrm{Kf}-2$ parasequence set. Flooding surfaces (heavy white lines), base of channels (dashed lines), lateral accretion within the fluvial channels (dotted lines), and significant bedding surfaces in shoreline units (thin white lines) are shown. 
on the measurements made in the field on location points which are visible in the photographs. Field-based topographic map tie points are also included as well as match points for adjacent photomosaics.

When completed, these photomosaics will be used for correlation, for development of cross sections, and for placement of the case-study areas into the regional setting. The photomosaics will be available on compact discs to researchers.

\subsection{Preliminary Regional Stratigraphic Interpretations}

The Ferron Sandstone was divided into parasequences and parasequence sets. Figure 2.2 shows all of the Ferron parasequences that have been recognized, named, and placed in their relative positions. The parasequences are described in the appendix of Chidsey and Allison (1996). The abundance of parasequences in parasequence sets $\mathrm{Kf}-1$ and $\mathrm{Kf}-2$, as compared to the younger parasequence sets, is striking. This is the result of two factors. First, $\mathrm{Kf}-1$ and $\mathrm{Kf}-2$ prograded farther than did the later parasequence sets and so would be expected to be made up of more "building blocks." The second factor is that the amount of relative sea-level rise that occurred during progradation was greater for the younger Ferron parasequence sets than it was for the older ones. This affected parasequence-level stratigraphy profoundly.

During progradation of parasequence sets $\mathrm{Kf}-1$ and $\mathrm{Kf}-2$, the supply of sediment was abundant compared to the creation of space in the basin to accommodate it. A relatively small amount of sediment was required to aggrade the coastal plain and a considerable proportion passed through the fluvial systems to reach the shoreline. Rapid supply of sediment at the river mouths promoted the building of river-dominated deltas, the deposits of which are conspicuously more abundant in $\mathrm{Kf}-1$ and $\mathrm{Kf}-2$ than they are in $\mathrm{Kf}-4$ through $\mathrm{Kf}-8$. It is highly probably that rises of relative sea level caused either by eustatic fluctuations or by pulses of basin subsidence continually affected the area and are the underlying mechanism for inducing parasequence-level transgressions and regressions. A delta is very much "at risk" should even a minor rise of relative sea level occur. Transgression of the coasts adjacent to a delta diminishes the river's already inefficient gradient, leading inevitably to avulsion of the river, abandonment of the delta, and rapid transgression across the delta plain. Many such transgressions are recognizable in $\mathrm{Kf}-1$ and $\mathrm{Kf}-2$.

The earliest, proximal part of each parasequence consists of deposits of wave-modified coasts. The relative sea level rises that brought about the parasequence-level transgressions caused reduction of sediment supply to the coasts. As the rise slowed and the balance shifted back to progradation, the supply of sediment to the coast increased. Initially, the supply was low, allowing extensive wave reworking. This also explains the pronounced seaward stratigraphic rise of many parasequences just seaward of their pinch-outs. The more distal parts of parasequences commonly contain deltaic deposits. At these times, the rates of rise of relative sea level were slower and the amounts of sediment delivered to the shorelines were correspondingly greater. The supply was great enough to allow progradation of recognizable deltas, particularly in the cases of parasequence sets $\mathrm{Kf}-1$ and Kf-2. 


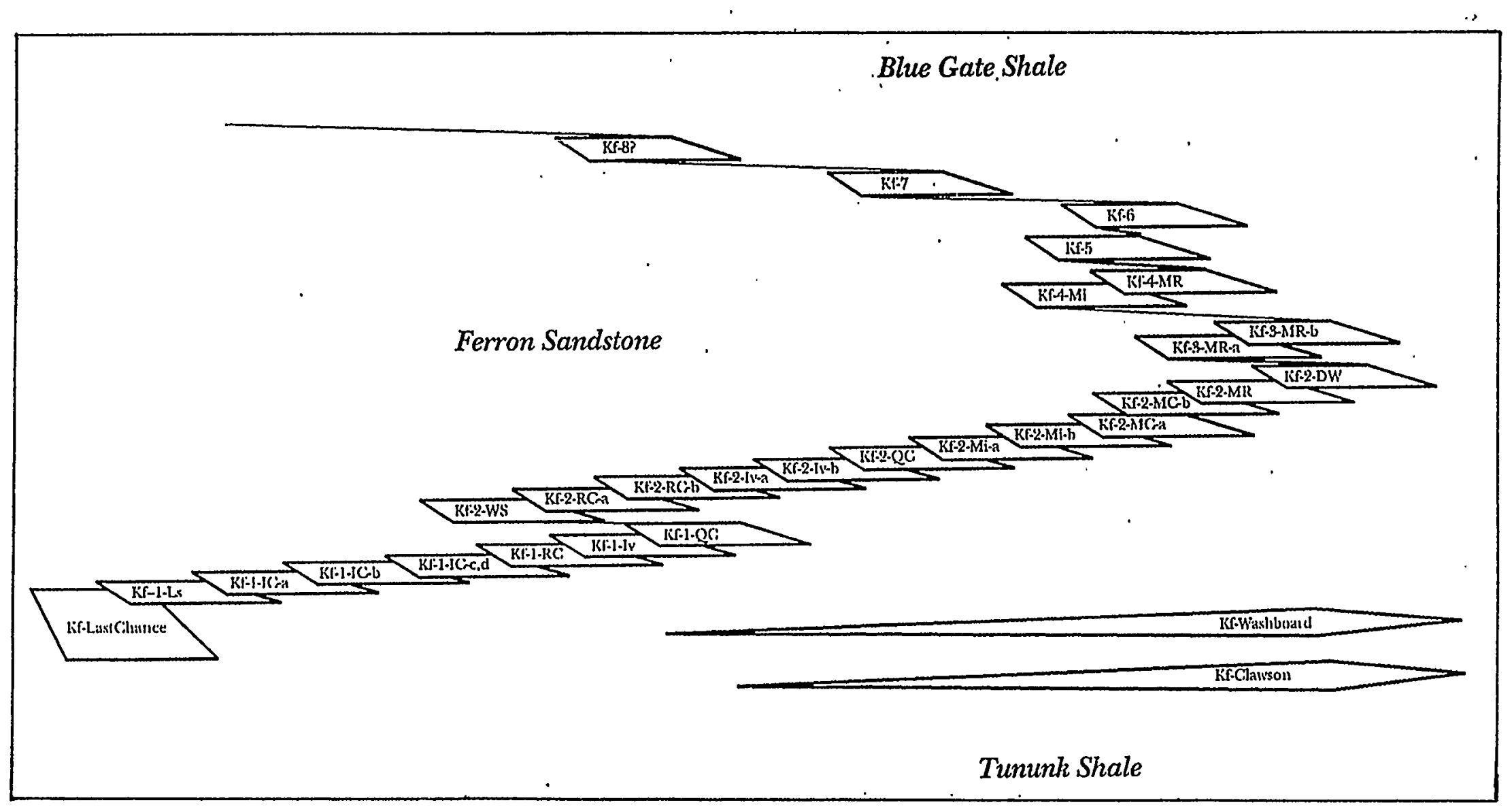

Figure 2.2. Diagram showing relative positions of Ferron parasequences and parasequence sets. The diagram has no scale. Landward is to the left, seaward to the right. The vertical axis is probably better equated to time than to rock section. Note that parasequence sets $\mathrm{Kf}-5$, $\mathrm{Kf}-6$, and $\mathrm{Kf}-7$ are presently not divided into parasequences. $\mathrm{Kf}-8$ is a shoreline sandstone unit that has been recognized but not yet formally incorporated into the scheme. 


\subsection{References}

Anderson, P.B., 1991, Landward pinch-out of Cretaceous marine nearshore clastics in the Ferron Sandstone Member of the Mancos Shale and Blackhawk Formation, east-central Utah; potential stratigraphic traps: Utah Geological Survey Contract Report 91-12, 110 p.

Barton, M.D., and Tyler, Noel, 1991, Quantification of permeability structure in distributary channel deposits Ferron Sandstone, Utah, in Chidsey, T.C., Jr., editor, Geology of east-central Utah: Utah Geological Association Publication 19, p. 273-282.

Chidsey, T.C., Jr., and Allison, M.L., 1996, Geological and petrophysical characterization of the Ferron Sandstone for 3-D simulation of a fluvial-deltaic reservoir - annual report for the period October 1, 1994 to September 30, 1995: U.S. Department of Energy, DOE/BC/14896$13,104 \mathrm{p}$.

Cotter, Edward, 1971, Paleoflow characteristics of a Late Cretaceous river in Utah from analysis of sedimentary structures in the Ferron Sandstone: Journal of Sedimentary Petrology, v. 41, no. 1, p. $129-138$.

--1975a, Deltaic deposits in the Upper Cretaceous Ferron Sandstone, Utah, in Broussard, M.L.S., editor, Deltas, models for exploration: Houston Geological Society, p. 471-484.

--1975b, Late Cretaceous sedimentation in a low-energy coastal zone: the Ferron Sandstone of Utah: Journal of Sedimentary Petrology, v. 45, p. 15-41.

--1976, The role of deltas in the evolution of the Ferron Sandstone and its coals: Provo, Brigham Young University Geology Studies, v. 22, pt. 3, p. 15-41.

Davis, L.J., 1954, Stratigraphy of the Ferron Sandstone, in Grier, A.W., editor, Geology of portions of the high plateaus and adjacent canyon lands, central and south-central Utah: Intermountain Association of Petroleum Geologists, Fifth Annual Field Conference Guidebook, p. 55-58.

Gardner, M.H., 1991, Siliciclastic facies architecture in foreland basin clastic wedges - field guide to the Ferron Sandstone Member of the Mancos Shale, east-central Utah: Boulder, Colorado School of Mines, unpublished report, $35 \mathrm{p}$.

Hodder, D.T., and Jewell, R.C., editors, 1979, Reclaimability analysis of the Emery coal field, Emery County, Utah: U.S. Bureau of Land Management EMRI Report No. 16, 408 p.

Ryer, T.A., 1981a, Deltaic coals of Ferron Sandstone Member of Mancos Shale: predictive model for Cretaceous coal-bearing strata of western interior: American Association of Petroleum Geologists Bulletin, v. 65, no. 11, p. 2323-2340. 
-1981b, The Muddy and Quitchupah Projects: a project report with descriptions of cores of the I, J, and C coal beds from the Emery coal field, central Utah: U.S. Geological Survey OpenFile Report 81-460, 34 p.

---1982a, Cross section of the Ferron Sandstone Member of the Mancos Shale in the Emery coal field, Emery and Sevier Counties, central Utah: U.S. Geological Survey Map MF-1357, vertical scale: 1 inch $=30$ meters, horizontal scale: 1 inch $=1.25$ kilometers.

-1982b, Possible eustatic control on the location of Utah Cretaceous coal fields, in Gurgel, K.D., editor, Proceedings of the 5th Symposium on the Geology of Rocky Mountain Coal: Utah Geological and Mineralogical Survey Bulletin 118, p. 89-93.

-1983, Transgressive-regressive cycles and the occurrence of coal in some Upper Cretaceous strata of Utah: Geology, v. 11, p. 207-210.

--1991, Stratigraphy, facies, and depositional history of the Ferron Sandstone in the canyon of Muddy Creek, east-central Utah, in Chidsey, T.C., Jr., editor, Geology of east-central Utah: Utah Geological Association Publication 19, p. 45-54. 


\section{CASE STUDIES}

Paul B. Anderson; Geological Consultant

Ann Mattson, C.B. Forster, S.H. Snelgrove, Richard Jarrard, and M.A. Chan; University of Utah

Thomas C. Chidsey, Jr.; Utah Geological Survey

and

J.A. Dewey, Jr., and T.H. Morris; Brigham Young University

The primary objective of the case studies is to develop a detailed geological and petrophysical characterization, at well-sweep scale or smaller, of the primary reservoir lithofacies typically found in a fluvial-dominated deltaic reservoir. Sedimentary structures, lithofacies, bounding surfaces, and permeabilities measured along closely spaced traverses (both vertical and horizontal) were combined with data from core drilling to develop a three-dimensional view of the reservoirs within each case-study area. In developing the characterization, an evaluation will be conducted on how variations in sedimentary structures and lithofacies influence both compartmentalization and anisotropy of permeability.

Two case-study areas were selected in 1994 for the project: Ivie Creek and Willow Springs Wash, in the central and southern parts respectively of the project study area (figure 1.1). The Ivie Creek case-study area was selected since it contains abrupt facies changes in the lower Ferron deltafront sandstones or parasequence sets in outcrops north of Ivie Creek, east of the mouth of Ivie Creek Canyon. Access to the area is excellent because of proximity to Interstate 70 (1-70). Willow Springs Wash is the largest of the two case-study areas. It covers an area 3.5 miles $(5.6 \mathrm{~km})$ long and 4 miles $(6.4 \mathrm{~km})$ wide (figure 1.1). The site was selected because of the excellent three-dimensional exposures in the Willow Springs Wash and Indian Canyon areas.

The Ferron Sandstone in the Ivie Creek case-study area consists of two regional scale parasequence sets, the $\mathrm{Kf}-1$ and $\mathrm{Kf}-2$. In the Ivie Creek case-study area the $\mathrm{Kf}-1$ parasequence set represents a river-dominated delta deposit which changes from proximal to distal from east to west. The $\mathrm{Kf}-2$ parasequence set represents a wave-modified deposit consisting of lower, middle, and upper shoreface, foreshore, and stream-mouth bar environments of deposition. Reservoir modeling is being conducted on data collected from and geological interpretations of the $\mathrm{Kf}-1$ parasequence set in the Ivie Creek case-study area. The modeling effort will concentrate on: (1) variations in fluid flow between the lithofacies, (2) the amount of communication between each parasequence, and (3) the effects the various bounding surfaces within parasequences would have on fluid flow in these units. Recommendations will be made on how bounding surfaces can be identified from core and well-log data and, ultimately, how such features should be considered in field development and secondary or enhanced oil recovery programs.

The focus of the work in the Willow Springs Wash case-study area will be parasequences of the $\mathrm{Kf}-1$ parasequence set in Indian Canyon. These rocks represent wave-modified shoreline deposition. No reservoir simulations will be conducted on data collected from the Willow Springs Wash area. However, the architectural elements interpreted from the outcrops here and the $\mathrm{Kf}-2$ at Ivie Creek will be incorporated into the overall reservoir model for the Ferron Sandstone. 


\subsection{Ivie Creek Case-Study Area}

Four primary activities were performed as part of the geological characterization of the Ferron Sandstone in the Ivie Creek case-study area: (1) drill-hole core descriptions, (2) lithofacies and paleogeographic interpretation, (3) petrophysical analyses, and (4) geostatistical analysis.

\subsubsection{Drill-Hole Core Description}

In September 1995, two stratigraphic test wells were drilled, logged, and plugged in the Ivie Creek case-study site: the Ivie Creek Nos. 10 and 11 (figure 3.1). These drill holes were located to evaluate the lithofacies and reservoir characteristics of the $\mathrm{Kf}-1$ and $\mathrm{Kf}-2$ parasequence sets. Core and geophysical logs will provide data for a three-dimensional morphologic interpretation of individual lithofacies and capture reservoir variations in the $\mathrm{Kf}-1$ and $\mathrm{Kf}-2$ parasequence sets over an area comparable in size to a small oil field.

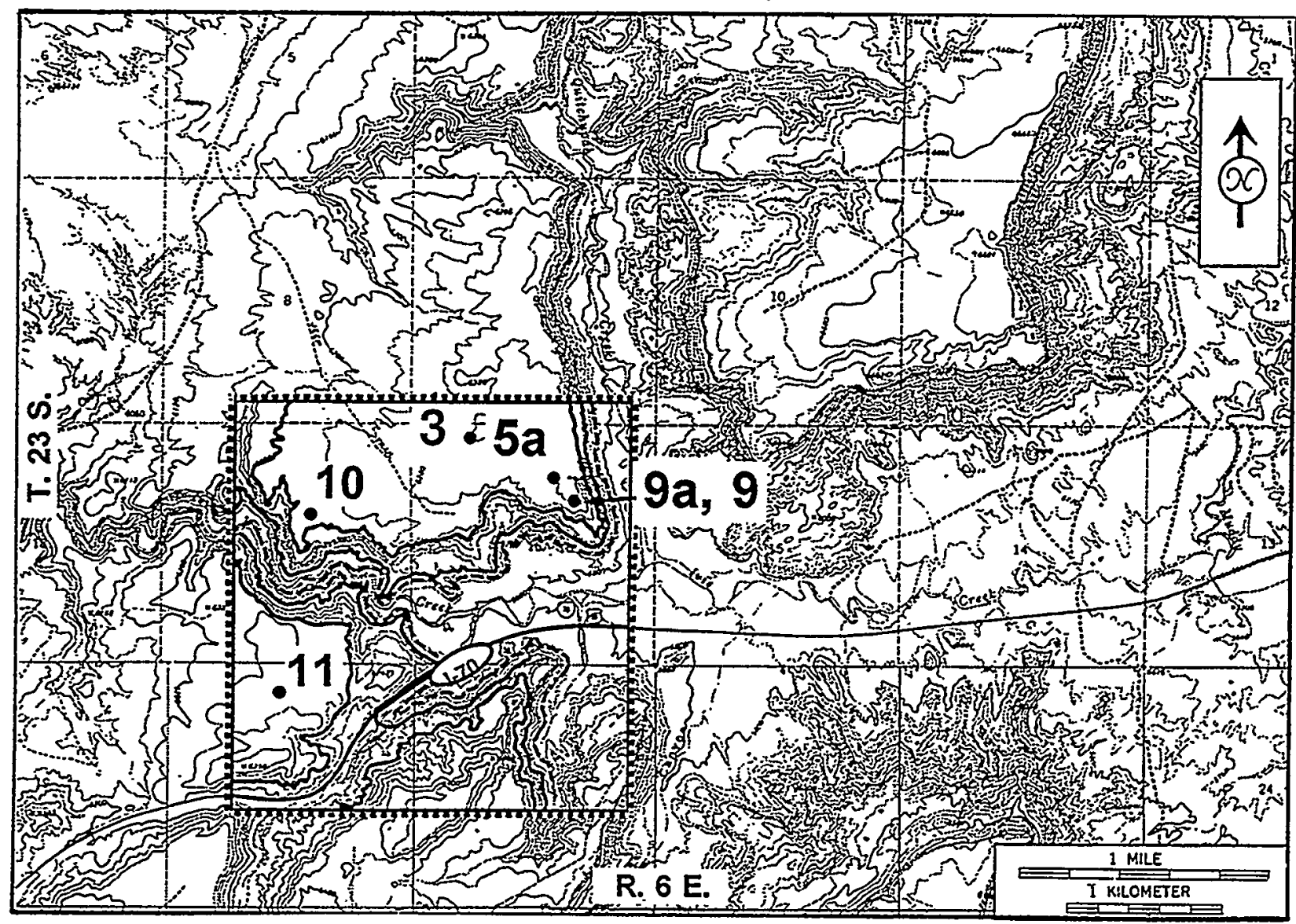

Figure 3.1. Locations of six drill holes in the Ivie Creek case-study area, sections 16, 17, and 20, T. 23 S., R. 6 E., Salt Lake Base Line, Emery County, Utah to evaluate the Kf-1-Iv and Kf2-Iv parasequence sets. A 2-mile-by 2-mile-(3.2-by 3.2-km) detailed, block is outlined. Base map from U.S. Geological Survey Mesa Butte and Walker Flat 7.5' topographic maps; contour interval is 40 feet $(12 \mathrm{~m})$. 
A total of 156 feet $(48 \mathrm{~m})$ of core was recovered from the Ivie Creek No. 11 drill hole (the Ivie Creek No. 10 was not cored). This core and core obtained from the 1994 drilling program (the Ivie Creek Nos. 3, 5A, and 9A [figure 3.1]) were described. Descriptions of the individual units in the core sections include the following information: (1) primary and secondary lithology, composition, color, and grain size of the rocks, (2) size, shape, and degree of induration of the beds, (3) sedimentary structures, biologic structures (trace fossils), and fossils in the rocks, and (4) bounding surfaces and depositional environment of the unit. Sections were correlated to develop preliminary interpretations of the stratigraphy and lithofacies.

Stratigraphic data from project drill-hole cores and four geophysical logs were transferred from the UGS database to software which drafted core sections and core descriptions (figure 3.2). This software generated graphic logs of core sections at scales of 1 inch: 2.5 feet and 1 inch: 10 feet. Logs at both scales contain attributes such as: lithology, sedimentary structures, and parasequence designations. General comments, grain sorting, grain roundness, and degree of consolidation were also noted on the 1 inch: 2.5 feet logs. The core sections were adjusted to match the gamma-ray log which was plotted to the left of the rock column. All attributes will be used to define reservoir components in the statistical and reservoir-modeling parts of the project.

\subsubsection{Lithofacies and Paleogeographic Interpretations}

3.1.2.1 Methods: Dimensional data and lithofacies of the Kf-1-Ivie Creek-a (Kf-1-Iv-a) parasequence in the Ivie Creek amphitheatre area are being used for paleogeographic interpretation and the detailed reservoir modeling exercise. Scaled line work on photomosaics for this area shows off-lapping packages of beds referred to as clinoforms. Most of the clinoform boundary lines on the photomosaics were based on data from measured sections or changes in permeability noted during the permeability transects. Where a visual (and qualitative) change in permeability is present corresponding to a line on the mosaic and a unit boundary in a measured section, the line was highlighted. If these conditions were not met the line was not highlighted. An estimated 80 plus percent of the lines on the interpreted mosaic were highlighted in the area of a measured section.

Two other higher order lines were also delineated. A line was marked where the tops of the clinoforms are truncated by erosional surfaces that extend for more than 300 feet $(91 \mathrm{~m})$ laterally. These erosional surfaces drop stratigraphically through the $\mathrm{Kf}-1-\mathrm{Iv}-\mathrm{a}$ and the separate distal lithofacies eventually become unrecognizable. The lines marking the tops of the clinoforms delineate larger packages of similar internal clinoform organization informally called subcycles.

Another highlighted line was used to designate a similar hierarchal package of rock or subcycle with a different upper bounding surface. In this case, the clinoforms do not appear to have been substantially eroded at the top. In the most proximal position, the bounding surface is overlain and underlain chiefly by sandstone. Progressing in a down-depositional direction, the lithology overlying the bounding surface becomes more shale dominated and a slope former on outcrop. In its most distal portion, this surface drops stratigraphically to a position within the lower third of bedding planes similar to the termination position of the other subcycle packages.

Clinoform boundaries in the $\mathrm{Kf}-1-\mathrm{Iv}-\mathrm{a}$ parasequence identified on photomosaics were digitized and scaled to: (1) provide internal consistency for spatial relationships of field data, (2) correct all photomosaic data for distortions, (3) tie to a common datum (the $\mathrm{Kf}-1 / \mathrm{Kf}-2$ parasequence set boundary), and (4) provide a framework for scaled cross sections and fence diagrams. 

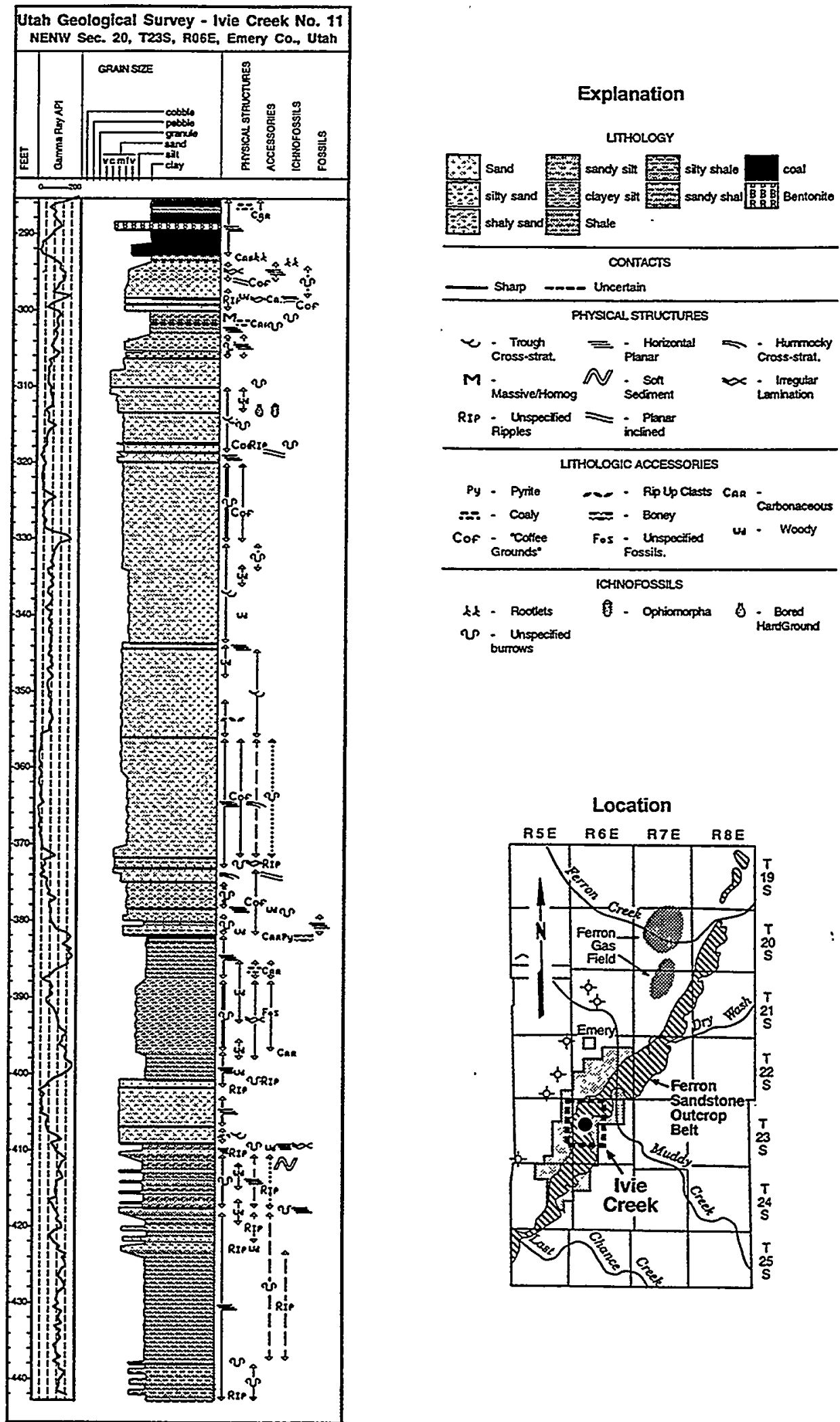

Figure 3.2. Graphic interpretation of core, with gamma-ray curve, from the Ivie Creek No. 11 drill hole, NE1/4NW1/4 section 20, T. 23 E., R. 06 E., Salt Lake Base Line, Ivie Creek casestudy area, Emery County, Utah. 
Elevation profile picks were positioned on the 7.5-minute topographic maps utilizing tie points on rock panels that were identified in the field. Location of photomosaics, wells, measured sections, and permeability transects were marked on a summary base map. The Kf-1-Iv-a outcrop location was marked and scaled on the base map using field-survey data. This effort included locating all measured points on photomosaics (approximately 200 points, spaced about 100 feet [30 $\mathrm{m}]$ apart) and converting these points to state plane $X-Y$ coordinates. The scaled, photomosaic line work was scanned into a well-log digitizing package to produce scaled Ivie Creek reconstructions (figure 3.3). Various units seen as open polygons on the reconstructions were closed for integration into the reservoir model.

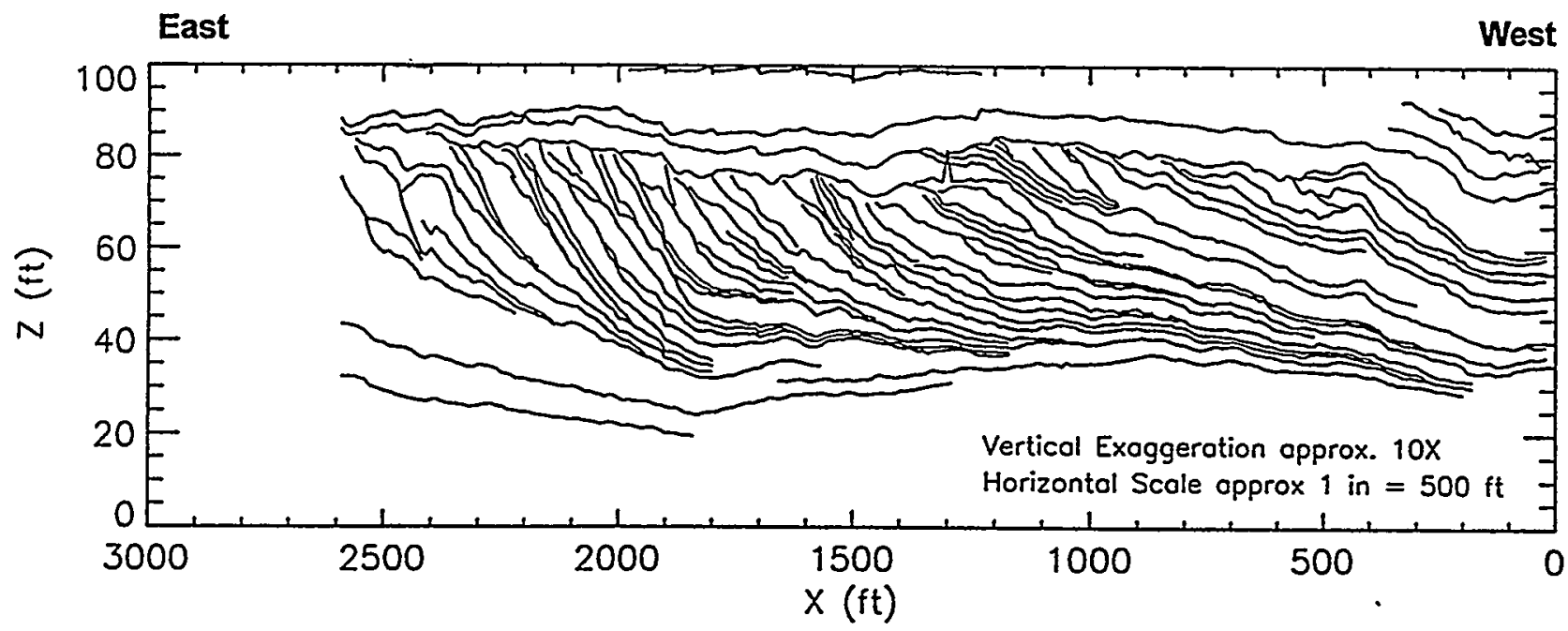

Figure 3.3. Scaled reconstruction of Ivie Creek photomosaic from scanned line work to be used for cross-section construction and reservoir modeling.

General lithofacies categories were assigned to units (polygons) on the scaled photomosaic panels based on geometry, sedimentary structures, and apparent shale content. Graphic logs along permeability transects and measured sections were adjusted to fit the scaled line work to form the base for construction of cross sections and the three-dimensional model of the reservoir architecture.

A 2,000 feet by 2,000 feet by 80 feet $(610 \times 610 \times 24 \mathrm{~m})$ block of the Kf-1-Iv-a parasequence, within the Ivie Creek amphitheatre, was selected as the site where detailed, three-dimensional geological and petrophysical models will be developed as input to a series of reservoir simulations (figure 3.4). Eight stratigraphic cross sections were constructed to define the three-dimensional volume. Two cross sections correspond to the south and east facing outcrops, four define the sides of the block, and two (tied into core holes) cut diagonally through the block. Each cross section was discretized into about 28 layers comprised of 20-feet- (6-m-) long, 4-feet- (1.2-m-) high, twodimensional blocks. Each block was assigned the dominant clinoform lithofacies within the block as an attribute for the whole block (figure 3.4). The next step in this process will be to discretized, in the same fashion, the volume between the cross sections for use in paleogeographic interpretation of parasequence subcycles and the detailed reservoir deterministic modeling exercise. 


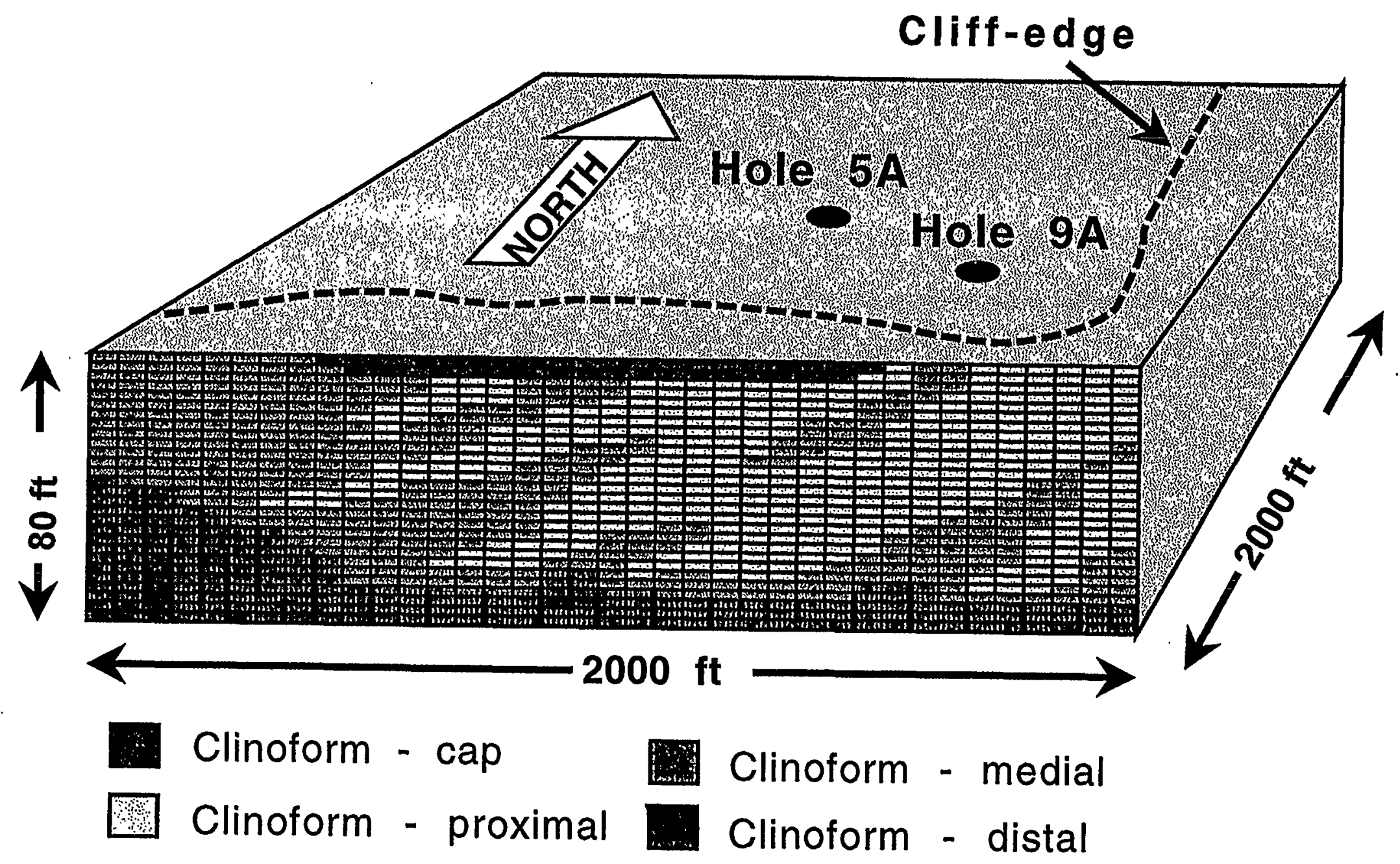

Figure 3.4. Schematic, discretized three-dimensional volume from the selected block of the Kf-1-Iv-a parasequence to be modeled within the Ivie Creek amphitheatre. 
3.1.2.2 Interpretation: With the line work in place and the integration of measured sections, permeability data, and line work and associated annotations, the clinoform section of Kf-1-Iv-a parasequence was classified into four lithofacies: clinoform proximal (cp), clinoform medial (cm), clinoform distal (cd), and clinoform cap (cc). Lithofacies $\mathrm{cp}, \mathrm{cm}$, and $\mathrm{cd}$ are assigned to clinoforms only, and lithofacies $\mathrm{cc}$ is a bounding facies above the clinoforms (figures 3.4 and $3.5 \mathrm{~A}$ ).

Lithofacies cp is mostly fine- to medium-grained sandstone. The chief sedimentary structure is low-angle cross-stratification with minor horizontal and trough cross-stratification and rare hummocky bedding. The lithofacies is dominantly thick- to medium-bedded, well to moderately indurated, with permeabilities ranging from 2 to 600 millidarcies (md) and a mean of about $10 \mathrm{md}$. The inclination of bed boundaries is generally greater than $10^{\circ}$. This lithofacies is interpreted to be the highest energy and most proximal to the sediment input point. The steep inclinations are interpreted to represent deposition into a relatively localized deep area in an open bay environment. The dominance of low-angle cross-stratification with inclinations within the bed or clinoforms in an up-depositional dip direction indicates the influence of on-shore wave energy.

Lithofacies $\mathrm{cm}$ is dominantly sandstone with about 5 percent shale. The sandstone is primarily fine-grained with slightly more fine- to very-fine-grained than fine- to medium-grained sandstone. Horizontal beds dominate with some rippled, trough cross stratification, and low-angle cross-stratification. Bed thicknesses range from laminated to very thick, but most are medium. The beds are generally well to moderately indurated but are occasionally friable. The permeability values range from non-detectable to $100 \mathrm{md}$ with the mean about $3 \mathrm{md}$. Inclination on the clinoform boundaries is between 2 and $10^{\circ}$. Lithofacies $\mathrm{cm}$ is generally transitional between lithofacies $\mathrm{cp}$ and cd, but occasionally is present at the erosional truncation or off-lapping boundary of the clinoforms, with no visible connection to lithofacies cp.

Lithofacies cd is sandstone (sometimes silty) with about 10 percent shale. The sandstone is dominantly fine- to very-fine-grained, with considerable variation. Sedimentary structures in this lithofacies are chiefly horizontal laminations and ripples in medium to thin beds. Beds range from well indurated to friable. Average lithofacies cd permeability is just at the detection limit of $2 \mathrm{md}$, but ranges up to $80 \mathrm{md}$. This lithofacies is gradational with lithofacies $\mathrm{cm}$ and represents the deepest water and lowest energy deposition within the clinoform. It can be traced distally into prodelta to offshore lithofacies.

Lithofacies cc consists of very-fine- to fine-grained, thick- to medium-bedded sandstone. The beds are horizontal, with some trough and low-angle cross-stratification. Burrowing is rare. The sandstone is mostly well indurated, with permeabilities ranging from non-detectable to 100 millidarcies (md) with a mean of about $2 \mathrm{md}$. This lithofacies is present stratigraphically above the truncated clinoforms near the top of the parasequence and where bed boundaries show little to no inclination. The cc lithofacies is interpreted to represent an eroded and reworked delta top.

The paleogeography of the Kf-1-Iv-a parasequence was determined by mapping five depositional time steps using photomosaics, measured sections, paleocurrent data, and lithofacies cross sections.. Figure 3.6 is a paleogeographic interpretation of the third time step of the Kf-1-Iv-a. The main delta lobe was located to the east and northeast. That delta lobe allowed a protected embayment to develop in the northwest part of the case-study area. The clinoforms observed in section 16 (figure $3.5 \mathrm{~A}$ ) represent deposition into the embayment fed by active channels to the southeast. The shallow marine and moderate-depth marine environments produced the clinoform proximal, medial, and distal lithofacies respectively. 


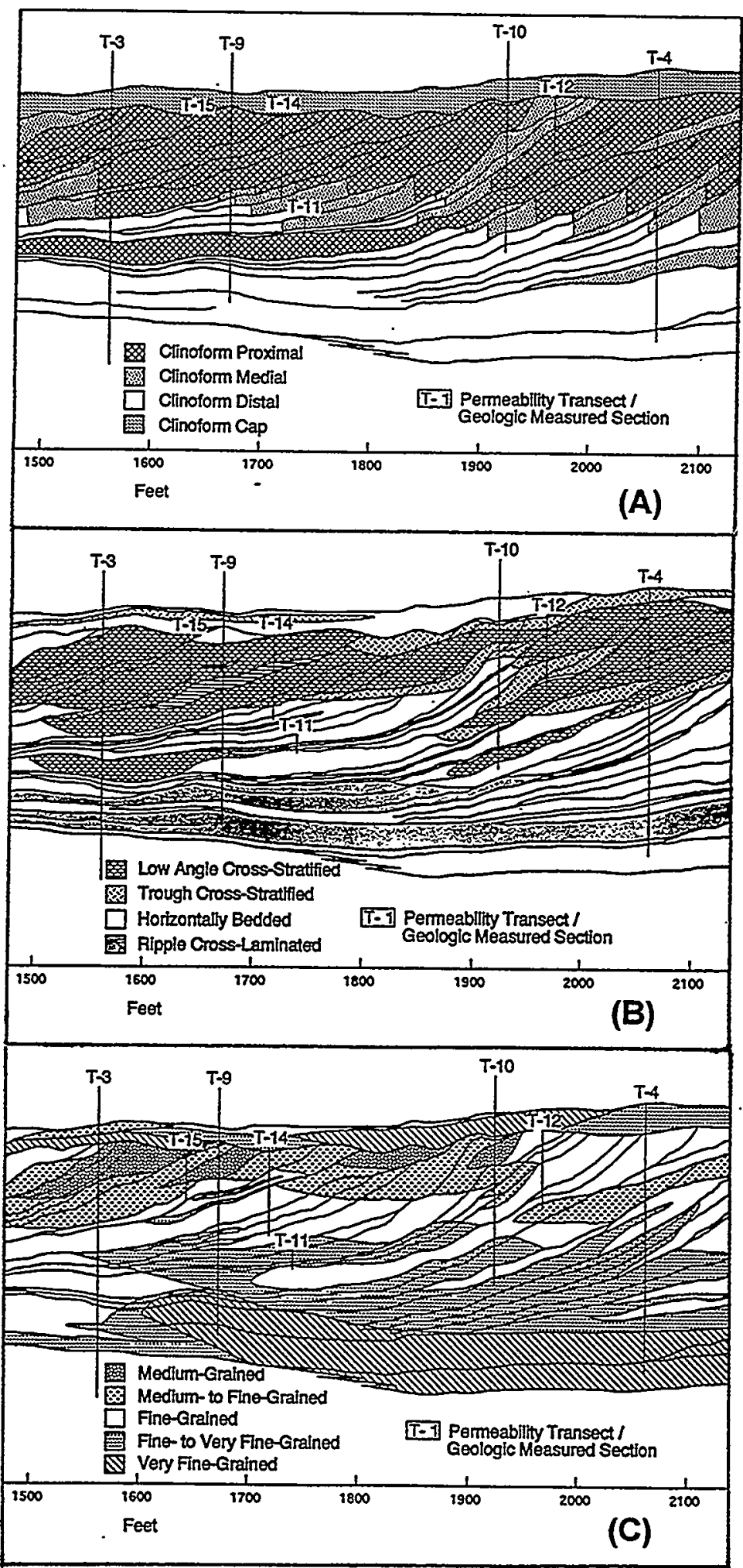

Figure 3.5. Scaled cross sections, oriented west to east, of the Kf-1-Iv-a parasequence from the Ivie Creek amphitheatre based on a portion of the interpreted photomosaic. Vertical lines represent permeability transect locations. (A) Cross section showing clinoform lithofacies assigned to the Kf-1-Iv-a parasequence. (B) Dominant sedimentary structure distribution within clinoform facies. (C) Average grain-size distribution within clinoform facies. See figure 4.1 2-D model domains for approximate location of these cross sections. 


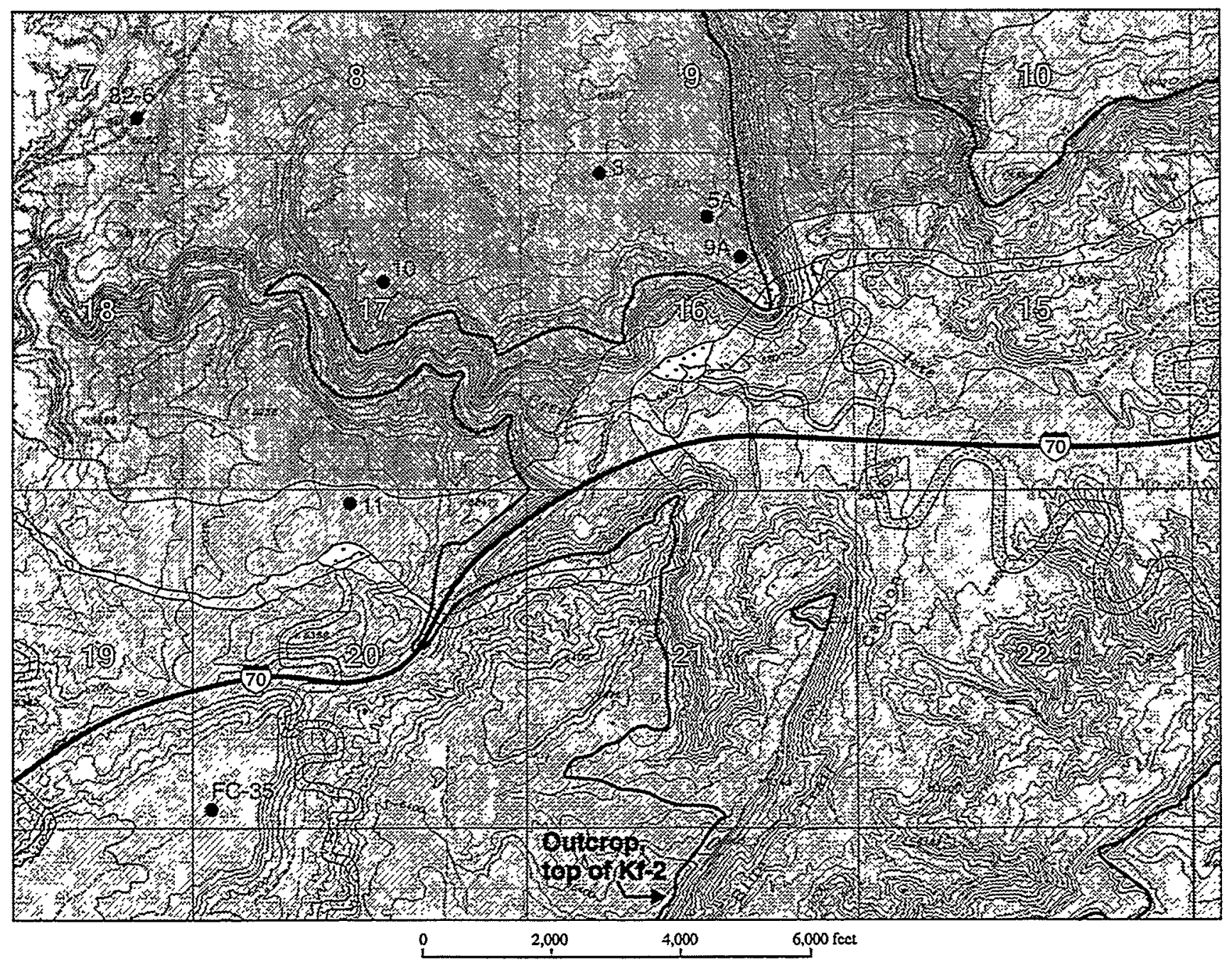

$\because \therefore \therefore$ Distributory complex
$\therefore \%$ Surf zone
6 Active channel

Coastal plain / swamp
Shallow marine
FC-35 Drill-hole location

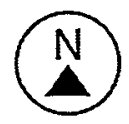

FC-35 Drill-hole location

Figure 3.6. Paleogeographic interpretation of the third of five time steps of the Kf-1-Ivie Creek-a parasequence. River channels flowing from the south and southeast deposited sands into a protected embayment in the northwest part of the area. 


\subsubsection{Petrophysical Analysis}

The objective of the petrophysical analysis of the Ferron Sandstone is to characterize the basic petrographic parameters, at the sweep scale or smaller, of the primary reservoir lithofacies typically found in fluvial-dominated reservoirs. Core plugs and thin sections selected from outcrop and drill-hole sampling in the Ivie Creek case-study area were analyzed to determine vertical and lateral variations in the petrophysical properties. The interrelations among these properties in the $\mathrm{Kf}-1$ and $\mathrm{Kf}-2$ parasequence sets are being evaluated.

3.1.3.1 Methods: Petrophysical measurements were made on 87 Ferron Sandstone core plugs collected from the Kf-2 parasequence set during the 1995 field season and processed through Amoco Production Research's Geoscience Evaluation Module (GEM). The measurements consisted of: (1) saturated, dry, and grain densities, (2) effective and Boyle's Law porosities, (3) air permeability, (4) magnetic susceptibility, (5) qualitative and quantitative mineralogy, (6) compressional and shear wave velocities as a function of effective pressure, and (7) thin-section-image analysis. The specific details of the GEM procedures used are given by Sondergeld and Rai (1988, 1993a, and 1993b). Velocities were measured using the pulse transmission technique of Schreiber and others (1973) and mineralogy was determined using a transmission infrared technique described by Griffiths and de Haseth (1986). Thin sections were made from selected core plugs having varied lithology, lithofacies, and.permeability values.

3.1.3.2 Results: The major findings from preliminary analyses of these data are: (1) clay content has little effect on velocity but carbonate cementation increases velocity (via its reduction of porosity, not by directly increasing rigidity modulus), (2) a major source of velocity dispersion is the expansion that these outcropping rocks have undergone due to uplift and erosional exhumation, (3) only carbonate content has a significant effect on porosity from possible mineralogic controls, (4) porosity strongly controls permeability, with kaolinite content a much smaller influence where diagenetic kaolinite blocks pore throats, and therefore decreases permeability, and (5) carbonate dissolution is a major control on Ivie Creek petrophysical patterns. The porosity and permeability of these rocks still retain their original link to grain size, in spite of subsequent cementation and carbonate dissolution, so the applicability of fluid-flow modeling of Ferron data to deep exploration plays is not strongly impacted.

Ferron well logs from outside the Ivie Creek case-study area were analyzed for comparison of petrophysical log responses to those observed in Ivie Creek core plugs and geophysical logs. The database search for all wells with both sonic and density logs of the Ferron identified 31 such wells. Twenty-four of these wells had accurate sonic and density logs with minimal gas effect. Velocities and densities for these wells were analyzed for velocity/porosity patterns which were compared to Ivie Creek data. A comparison was made of the continuous-core compressional velocity measurements to velocity and density measurements from geophysical logs from the Ivie Creek No. 3 drill hole (figures 3.1 and 3.7). Agreement is generally good despite the different measurement techniques and the different measurement volumes. 


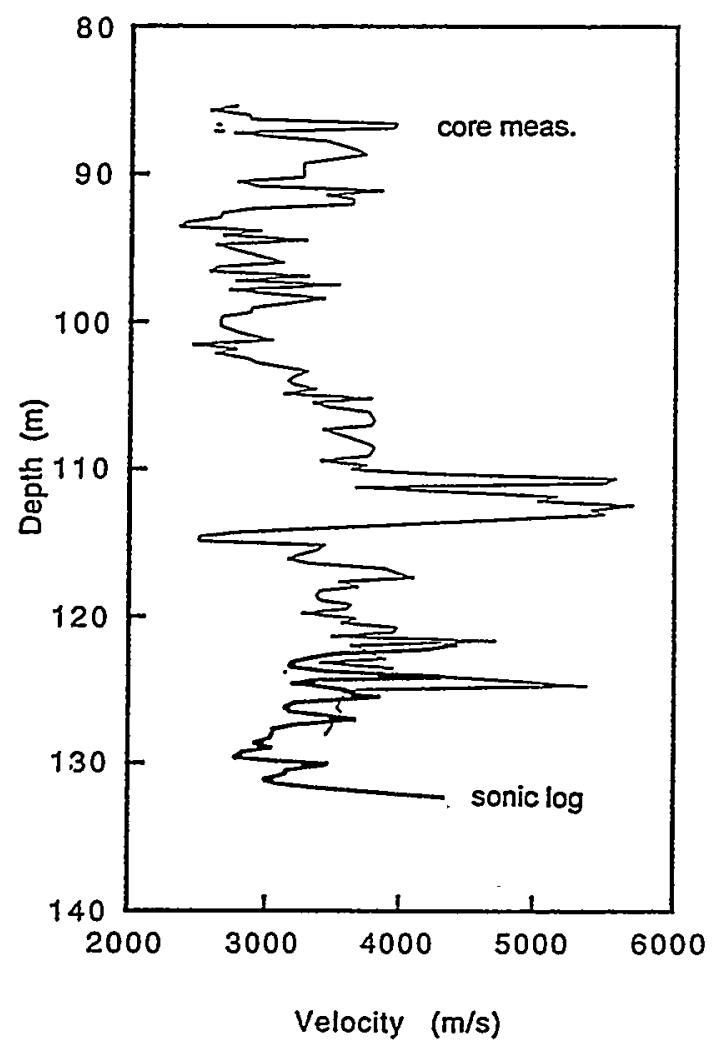

(A)

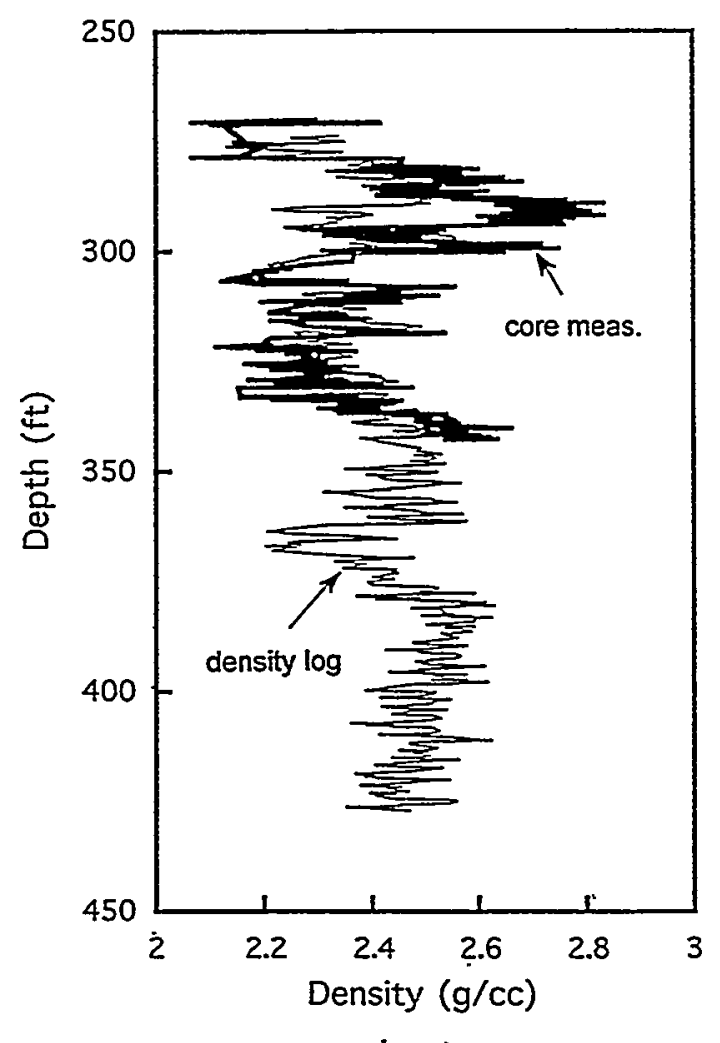

(B)

Figure 3.7. Comparisons of geophysical log and continuous-core measurements, for both velocity and density, at the Ivie Creek No. 3 drill hole (see figure 3.1 for location).

From thin sections, all Ferron samples fall within the broad category of quartzo-feldspathic arenites, although they vary in percentage of grain types. The sorting of most of the Ferron samples is moderate, with $\mathrm{Kf}-2$ shoreface sandstones (hummocky cross-stratified, horizontally bedded, or bioturbated) tending to be the "cleanest." This is to be expected given that the Kf-2 are from wavedominated (and reworked) sediments. The Kf-1 parasequence set samples are typically "dirtier", contain more lithics and altered grains, and are more compact (probably due to rapid sedimentation from fluvial-dominated deltas).

Very little if any primary porosity remains in any of the samples. Almost all the porosity of any significance is secondary porosity controlled by the dissolution of carbonate phases (carbonate, dolomite, and possibly siderite). Where such secondary porosity is present, mostly quartz and clay (kaolinite) cements remain with some interspersed minor carbonate and/or iron cement.

There appears to be a strong correlation between porosity and grain size in that the coarser grain sizes (generally fine to medium or coarse) tend to have more and larger pores. Coarser grained sandstones tend to be more quartz rich and are relatively "cleaner" with less matrix. Organic matter may form small-scale permeability barriers, and it is noted that coarser grained samples with better porosity generally contain less organic matter. Fine-grained samples tend to have more organic matter as well as more concavo-convex grain contacts resulting in reduced porosity. 
Eighteen thin sections were made from selected sandstone core plugs with varied lithology, delta-front position, and permeability values in the Ivie Creek Kf-1-Iv-a parasequence. The sandstone samples ranged from largely very fine grained to medium grained with some silt and coarse-sand fractions. The samples are typically quartz arenite to quartzo-feldspathic arenite. Most samples are poorly to moderately sorted with varying degrees of rounding. Most samples show a moderate to strong degree of compaction.

Petrographic analysis of the sandstones indicates a complex diagenetic history with as many as five stages of cementation. Quartz overgrowths in Ferron Sandstone thin sections probably represent an early diagenetic stage. Calcite cement and dolomite rhombs are middle diagenetic stages, followed by late phases of iron/hematite staining or replacement of the carbonate minerals (such as the dolomite rhombs). Final stages of diagenesis are dissolution of those same carbonate phases and development of microfractures. Some grains of feldspar were altered to clay and/or replaced by carbonate. Squashed rock fragments are common. Many of the samples have undergone significant compaction leaving little remaining primary porosity. Porosity values are variable, but generally less than 15 percent. There is considerable secondary porosity development which is evidenced by dissolution of carbonate minerals. Much of this secondary porosity development is unevenly distributed.

An "unexpected" petrographic find was from a rippled sandstone with a relatively high permeability value that can be attributed to small (microscopic) microfractures (approximately 0.2 $0.4 \mathrm{~mm}$ thick) filled with gypsum. These gypsum veins run parallel to the bedding and contain secondary porosity (through dissolution) between some of the gypsum crystals. These veins probably act as conduits for fluid migration through an otherwise low permeability sample composed of fine-grained sandstone with its intergranular porosity occluded by calcite and dolomite cements.

\subsubsection{Geostatistical Analysis}

Spatial variations in lithofacies, stratigraphic thickness, sedimentary structures, and permeability data are being quantified through geostatistical analysis. The statistical variability of this information is needed for defining individual petrophysical units within the Ivie Creek casestudy area and for predicting the three-dimensional distribution of each unit. The statistical modeling is an important step in developing procedures for "scaling up" from the observational scale to that of a typical reservoir.

Geostatistical work was devoted to: (1) investigating statistical relationships between geologic features and permeability data, and among various geologic features for the Kf-1-Iv-a parasequence and $\mathrm{Kf}-2$ parasequence set in the Ivie Creek case-study area, and (2) populating the Kf-1-Iv-a parasequence with petrophysical data. Statistical analyses included: (1) summary statistics (mean, median, and others) for each parasequence and lithofacies, (2) histograms, (3) cumulative probability plots, (4) relative percentage bar plots, and (5) cross plots.

3.1.4.1 Methods: Geostatistical analysis required quantification of field data and synthesis of defined lithofacies. The UGS database, composed of geological and petrophysical megascopic observations within the defined lithofacies, was used to generate graphical representations showing spatial variations and relationships of sedimentary structures, grain size, and sand/shale ratios.

In order to run fluid-flow simulations for the three-dimensional facies model, the model must be populated with petrophysical data. The approach to be used requires that each lithofacies within 
the model be populated by the geometric mean of the permeability data. The geometric mean of the data is utilized in regions where fluid flow is neither parallel nor perpendicular to the strata. Plotting the permeability data for each facies on a log-normal plot show data spikes at about 2 md and 0.5 md that corresponds to instrument limits. Permeability values exhibit log-normal distributions with respect to sedimentary structure and grain size, and a less clear relationship with respect to bed size and induration.

When grouped by clinoform lithofacies, permeability values exhibit a log-normal distribution where mean permeability value decreases with decreasing depositional energy. An approach to account for these values, is to model these low permeability values by extrapolating the log-normal trend observed in the higher permeability values (figure $3.8 \mathrm{~A}$ ). The $\mathrm{Kf}-2$ is a wave-modified, fluvial-deltaic system as compared to the $\mathrm{Kf}-1-\mathrm{IV}-\mathrm{a}$ which is a fluvial-dominated system. This difference is reflected in the cumulative permeability plots that show much higher values for the Kf2 then for the $\mathrm{Kf}-1-\mathrm{Iv}-\mathrm{a}$ (figure 3.8B). The lithofacies identified within the permeability transect data range from lower shoreface to foreshore, mouth-bar, bay, and transgressive facies (figure 3.8C).

Lithofacies panels (lithofacies, sedimentary structures, and grain sizes) for the Ivie Creek amphitheatre were used to generate a deterministic distribution of permeability. Each of three panels - was discretized into 4 feet by 4 feet $(1.2 \times 1.2 \mathrm{~m})$ blocks and a number code was assigned for each attribute (for example clinoform proximal [CP] lithofacies $=2$ ). These attribute values were loaded into the computer with accompanying spatial coordinates. The rules for assigning permeability values to each block were calculated from the transect data. Geometric mean permeability values were calculated for all known combinations of facies, sedimentary structures, and grain size.

3.1.4.2 Results: The results of statistical analyses of sedimentary structures and grain sizes were applied to the four lithofacies assigned to the clinoforms of the $\mathrm{Kf}-1-\mathrm{Iv}$-a parasequence (figure 3.5). Each clinoform lithofacies in the $\mathrm{Kf}-1-\mathrm{Iv}$-a parasequence is characterized by a particular suite of geologic features as shown in the summary plots of figure 3.9 and the cross sections in figure $3.5 \mathrm{~B}$ and $\mathrm{C}$. There are distinct relationships between depositional energy, sedimentary structure, average grain size, and lithology; weaker correlations exist for induration and bed size. The relative frequency of sedimentary structures was calculated for the four lithofacies (figures 3.9A and 3.5B). Horizontal bedding is the most common sedimentary structure in all lithofacies. Ripple crosslaminated beds are most common in the clinoform distal lithofacies (cd). Low-angle and troughcross-stratified beds are common only in the clinoform proximal lithofacies (cp). The grain-size distributions (based on megascopic observations) were also calculated for the four lithofacies (figures $3.9 \mathrm{~B}$ and $3.5 \mathrm{C}$ ). As expected, the clinoform proximal lithofacies contains the coarsest material and the clinoform distal lithofacies the finest. The proximal sandstones also contained the greatest variations in grain sizes.

Each parasequence of the $\mathrm{Kf}-2$ parasequence set is also characterized by a particular suite of lithofacies, grain sizes, and sedimentary structures as shown in the summary plots of figure 3.10. The major lithofacies in the parasequences of the $\mathrm{Kf}-2$ is middle shoreface followed by distributarymouth bar and lower shoreface (figure 3.10A). The grain-size distributions (based on megascopic observations) were calculated for the four parasequences (figure 3.10B). The primary control on permeability is grain size. However, data analysis implies that grain sorting also plays a role. The relative frequency of sedimentary structures was calculated for the four parasequences (figure 3.10C). Bioturbation is the most common sedimentary structure in three of the parasequences followed by horizontal and trough-cross-stratified bedding. 


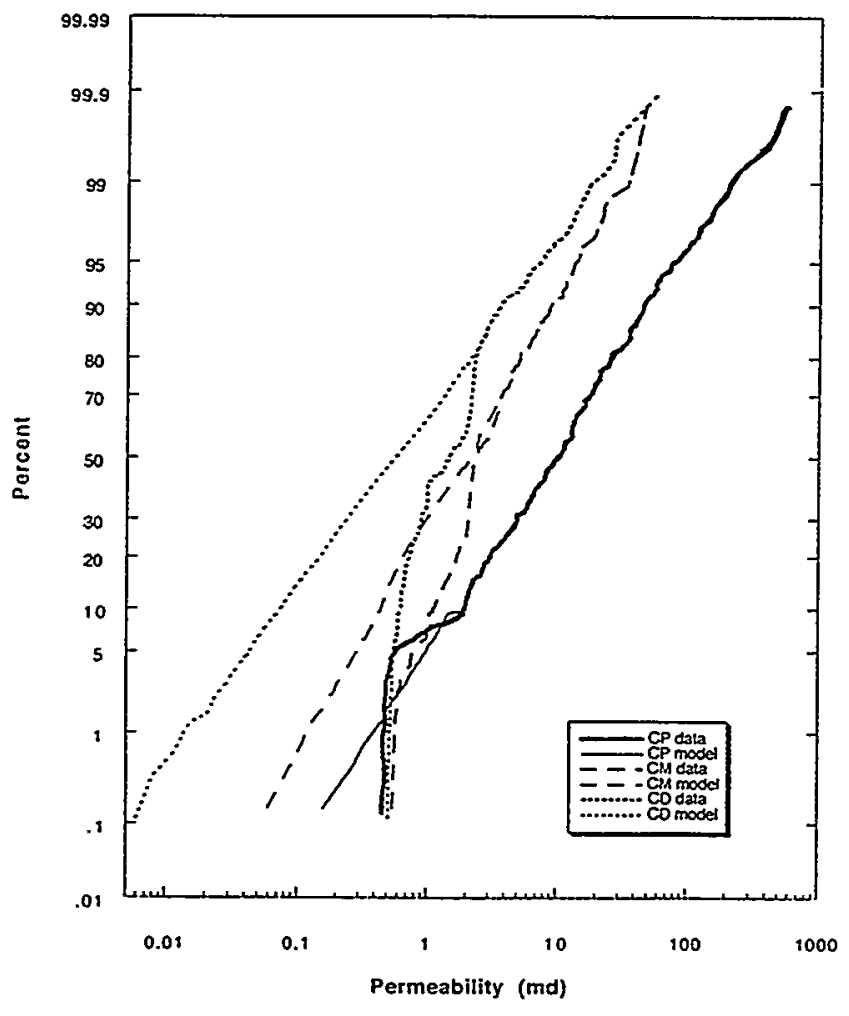

(A)

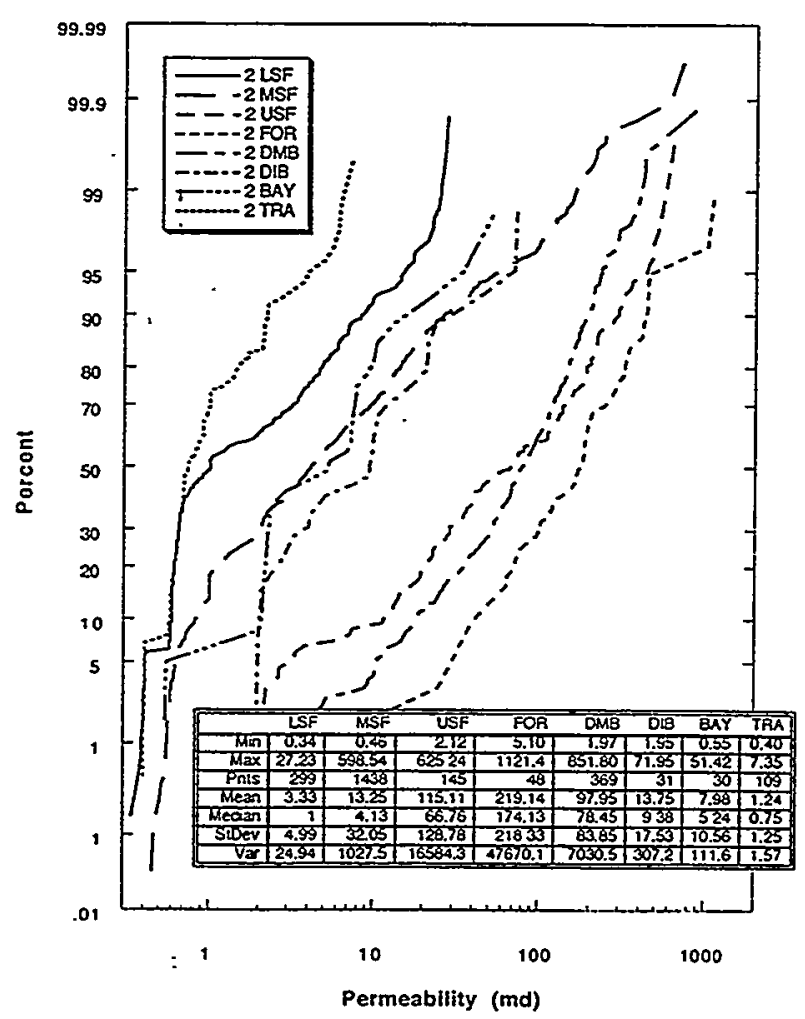

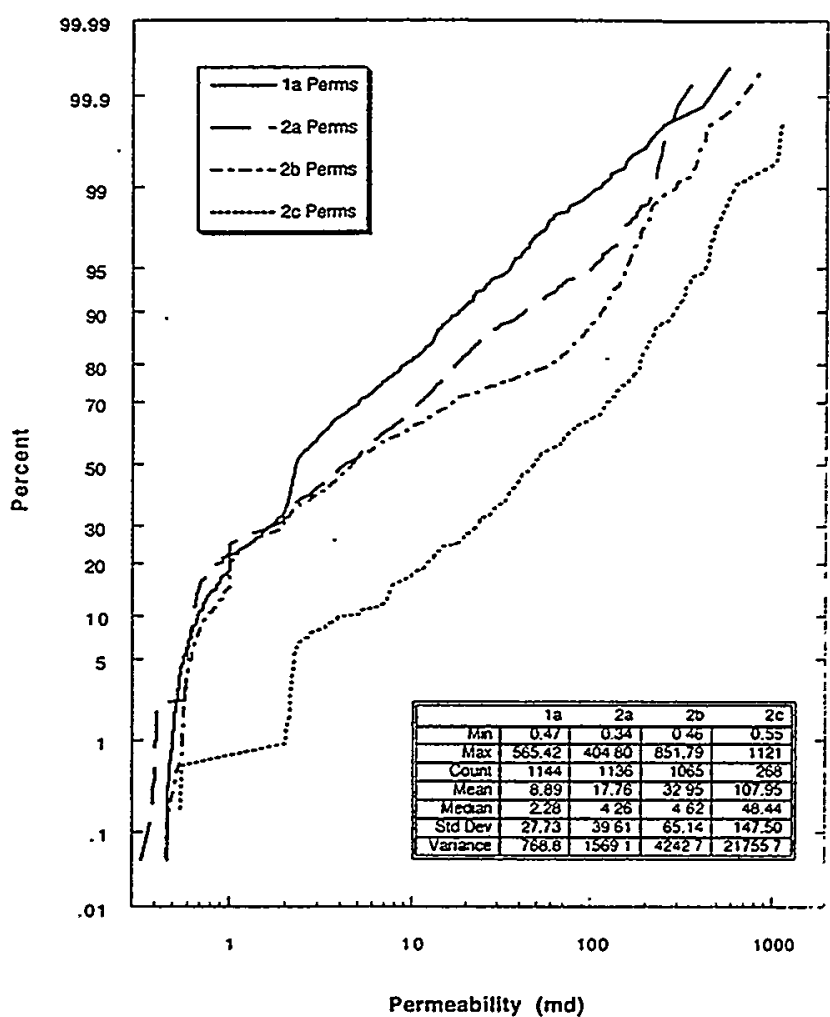

(B)

Figure 3.8. Cumulative percent permeability plots from the Ferron Sandstone, Ivie Creek case-study area: (A) model data and raw data from the Kf-1-Iva parasequence, (B) raw data from the Kf1-Iv-a parasequence and the $a, b, c$ parasequences of the $\mathrm{Kf}-2$, and (C) lithofacies versus permeability from the Kf2. Abbreviations for lithofacies: CP clinoform proximal, $\mathbf{C M}$ - clinoform medial, CD - clinoform distal, LSF - lower shoreface, MSF - middle shoreface, USF upper shoreface, FOR - foreshore, DMB distributary-mouth bar, DIB - distalmouth bar, BAY - bay-fill, and TRA transgressive.

(C) 


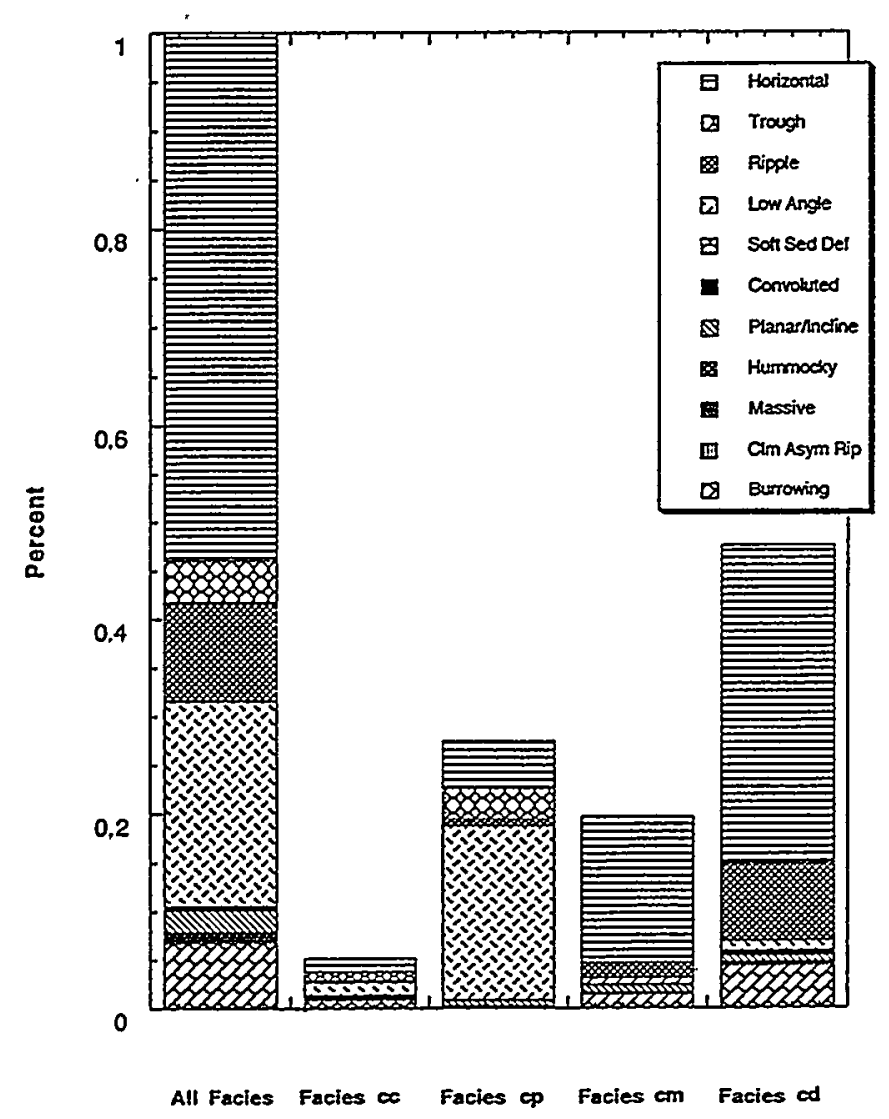

(A)

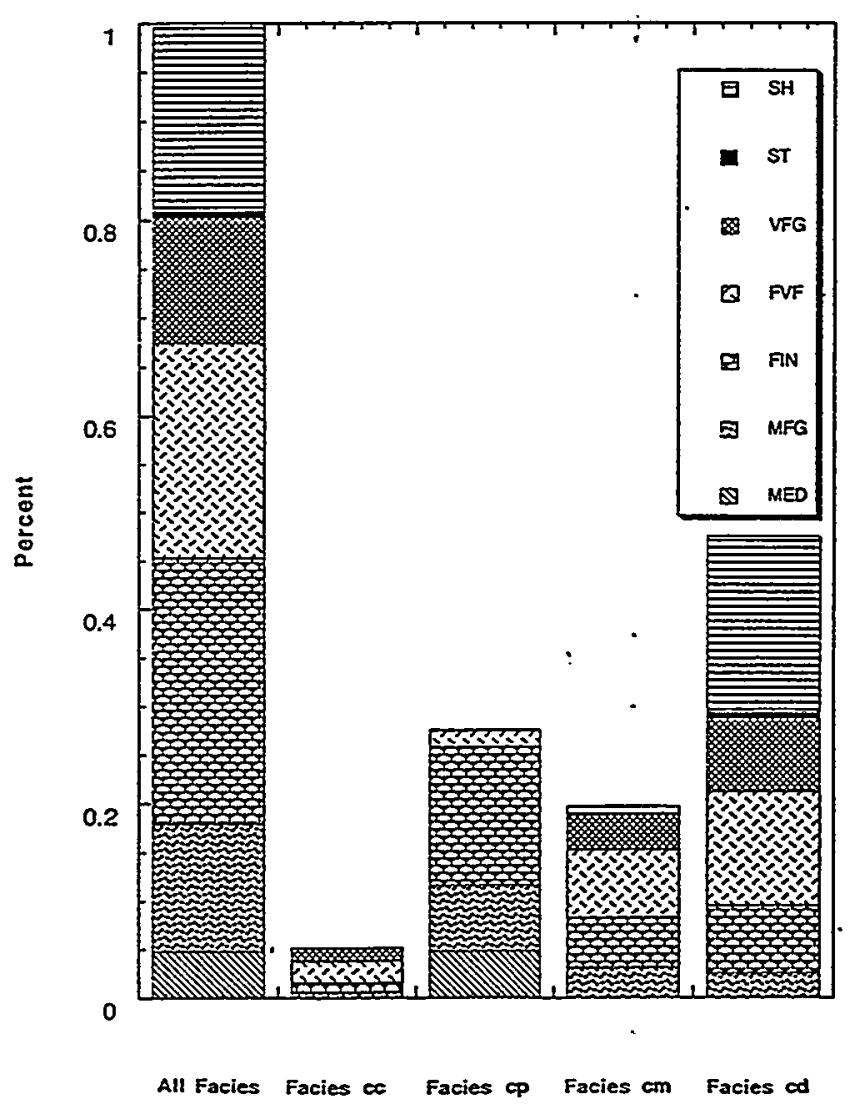

(B)

Figure 3.9. Statistical analyses of the clinoform lithofacies from the Kf-1-Ivie Creek-a parasequence: $(A)$ histogram showing relative frequency of sedimentary structure versus lithofacies, and (B) histogram showing grain-size distributions (megascopic observations) in each lithofacies $(\mathrm{SH}=$ shale, $\mathrm{ST}=$ silt, VFG = very fine grain, $\mathrm{FVF}=$ fine to very fine grain, FIN = fine grain, $M F G=$ medium to fine grain, and MED = medium grain. Abbreviations for lithofacies: CC - clinoform cap, CP - clinoform proximal, CM - clinoform medial, CD clinoform distal. 


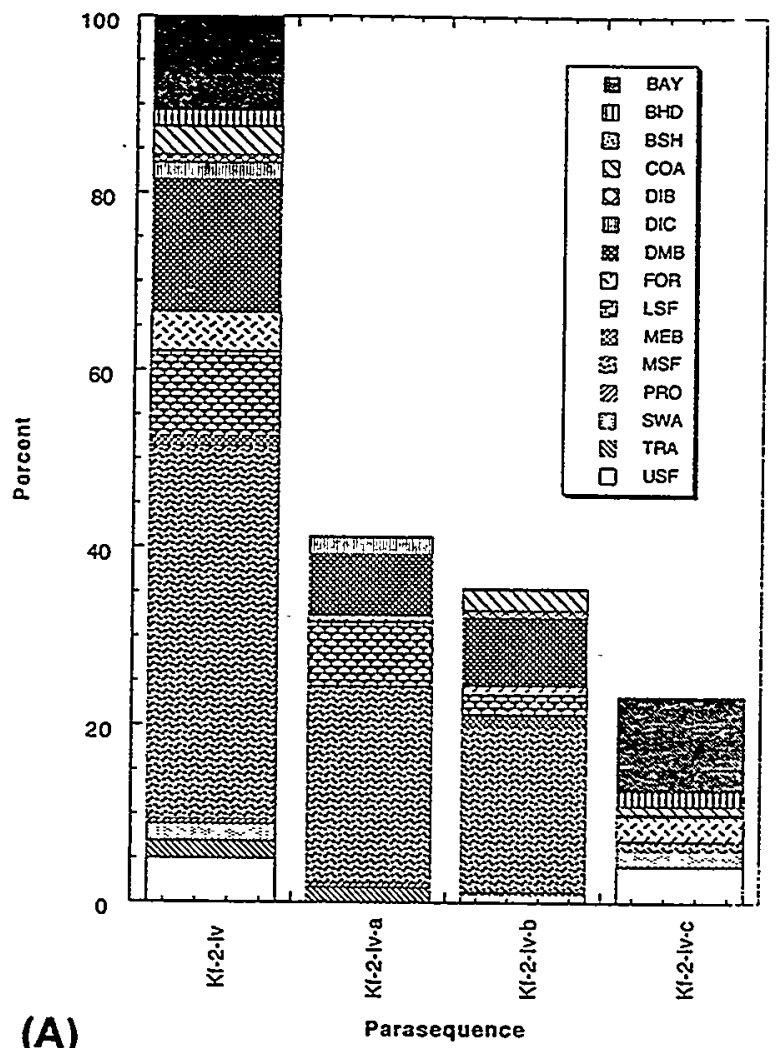

(A)

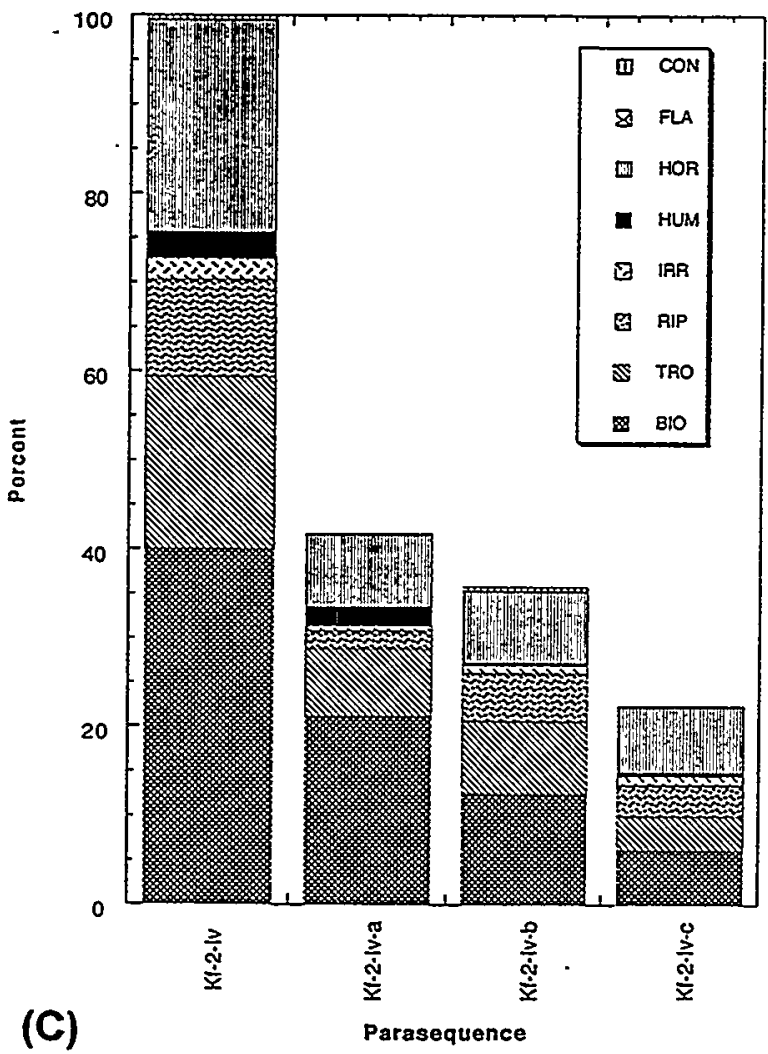

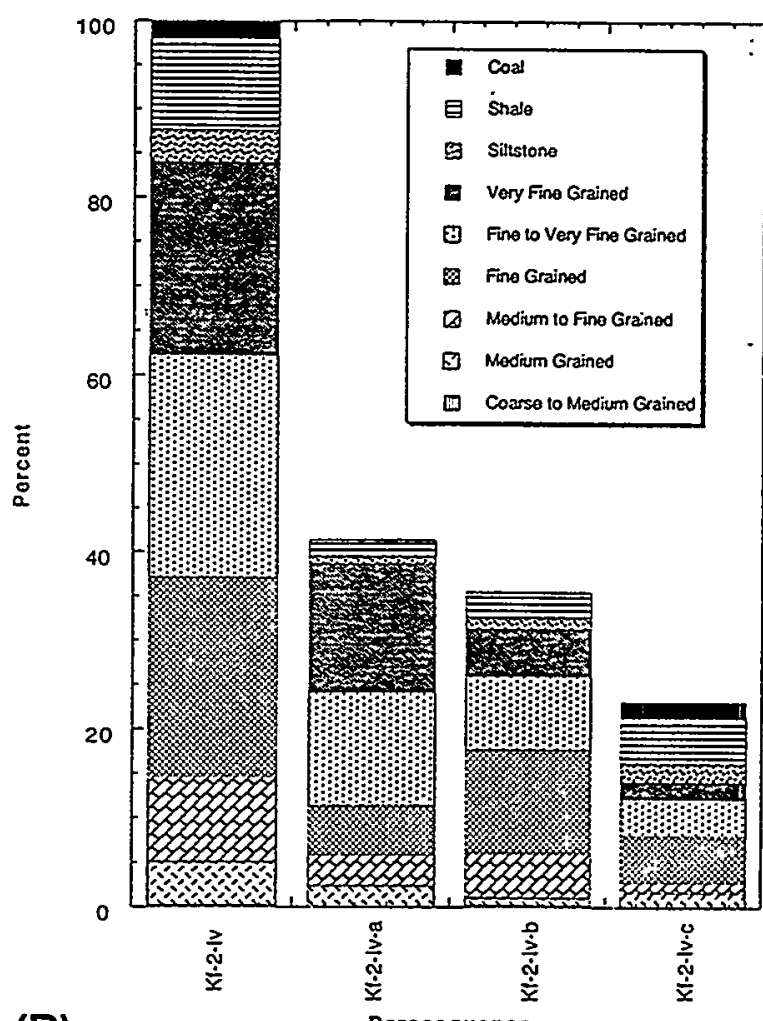

(B)

Figure 3.10. Statistical analyses of the Kf-2 parasequence set as a whole and the three parasequences within it ( $a, b$, and $c)$, Ivie Creek case-study area: (A) histogram showing lithofacies distribution, (B) histogram showing grain-size distributions (megascopic observations), and (C) histogram showing relative frequency of sedimentary structures. Abbreviations for lithofacies: BAY - bay-fill, BHD - bay-head delta, BSH - backshore, COA coastal plain, DIB - distal-mouth bar, DIC distributary channel, DMB - distributary-mouth bar, FOR - foreshore, LSF - lower shoreface, MEB - meander belt, MSF - middle shoreface, PRO - prodelta, SWA - swamp, TRA transgressive, and USF - upper shoreface. Abbreviations for sedimentary structures: CON convoluted/contorted, FLA - flaser bedded, HOR - horizontally bedded, HUM - hummocky crossstratified, IRR - irregularly laminated, RIP ripple cross-laminated, TRO - trough-crossstratified, and BIO - bioturbated. 
A look at the stratigraphic sections reveals overall coarser grain-size and a higher degree of bioturbation (figure 3.10C) than in the $\mathrm{Kf}-1-\mathrm{Iv}$-a analysis (figure 3.9A). A comparison of average permeability values for a given grain size/sedimentary structure combination suggests that for a specific grain size, permeability decreases as the sorting of the sedimentary structure decreases.

\subsection{Willow Springs Wash Case-Study Area}

Three primary activities were performed as part of the geological characterization of the Ferron Sandstone in the Willow Springs Wash case-study area: (1) photomosaic interpretation, (2) lithofacies description, and (3) paleogeographic mapping.

\subsubsection{Methods}

Work during the project year consisted of processing and interpreting the data collected from the Indian Canyon portion of the area during the previous field seasons and detailed photomosaics. Particular attention was paid to developing depositional models for the Kf-1-Indian Canyon-c and $\mathrm{Kf}-1$-Indian Canyon-d (Kf-1-IC-c and Kf-1-IC-d) parasequences. This was done primarily by comparison of the collected data with models developed from non-barred and barred, wavedominated shorelines and shorelines with varying amounts of tidal influence. Based on the conclusions from the aforementioned efforts, paleogeographic maps have been constructed that illustrate the evolution of depositional environments within the case-study area.

\subsubsection{Interpretation}

The Kf-1-IC-c parasequence has been interpreted as a wave-modified shoreline. A tidal inlet developed during early deposition of the parasequence. Later, as longshore currents caused the inlet to migrate towards the southeast, deposition along a wave-dominated shoreline became the dominant process. Seaward of this tidal inlet, a thick section of dominantly seaward- oriented trough or tabular cross-stratified sediment overlain by a thinner section of landward and more random oriented crossstratified sediment implies that modification of this model might be warranted. Work on non-barred coasts by Clifton and others (1971) suggests that as waves approach a shoreline, the sequence of sedimentary structures that develops includes a section of landward-oriented cross-beds. This is the opposite of what is seen in Indian Canyon. Hunter and others (1979) described deposits of barred shorelines displaying a significant seaward-oriented, cross-bedded section. Seaward-oriented bedforms, in this case, represent deposition on rip-channel mouth bars or within longshore troughs. Evidence of repeated scour and fill, developed as rip-channels migrated along the shoreline, would help to confirm this. This type of scour and fill has not been observed.

Another possible model for these deposits is an ebb-tidal delta. Ebb-tides would account for the seaward-oriented cross-beds present within Indian Canyon exposures. Additionally, a smaller section of landward-oriented cross-beds present above this, and below the foreshore deposits, could be explained by the presence of swash bars associated with the ebb-tidal delta. This model implies generally higher tidal ranges for the Ferron Sandstone, however, Miles O. Hayes, RPI, International, Inc., (verbal communication, 1996) has shown that tide ranges fluctuate due to coastal 
geomorphology and are accentuated within bights or embayments. Ryer and McPhillips (1983) have suggested that such a bight was present along the Ferron coastline at this time. Further, the spatial association of the seaward-oriented trough cross-stratification with a known tidal inlet should be incorporated in the depositional model. An ebb-tidal delta model incorporates all of these constraints.

Preservation of ebb-tidal deltas is relatively low in modern environments. Heward (1981) suggests that preservation of ebb-tidal deltas is higher along prograding shorelines. It is certain that this shoreline prograded, and the upward- and seaward-stepping parasequence architecture suggests that sedimentation was overwhelming sea-level rise.

Realistically, a hybrid of the wave-modified shoreline and ebb-tidal delta models may have produced the observed features in Indian Canyon. Slight differences in the depositional model may effect hydrocarbon reservoir potential, however, evidence to eliminate either model may be nonexistent.

\subsection{References}

Clifton, H.E., Hunter, R.E., and Phillips, R.L., 1971, Depositional structures in the non-barred highenergy nearshore: Journal of Sedimentary Petrology, v. 41, p. 651-670.

Griffiths, P.R., and de Haseth, J.A., 1986, Fourier transform infrared spectrometry: JohnWiley, New York, $656 \mathrm{p}$.

Heward, A.P., 1981, A review of wave-dominated clastic shoreline deposits: Earth Science Reviews, v. 17, p. 223-276.

Hunter, R.E., Clifton, H.E., and Phillips, R.L., 1979, Depositional processes, sedimentary structures, and predicted vertical sequence in barred nearshore systems, southern Oregon coast: Journal of Sedimentary Petrology, v. 49, p. 711-726.

Ryer, T.A., and McPhillips, Maureen, 1983, Early Late Cretaceous paleogeography of east-central Utah, in Reynolds, W.M., and Dolly, E.D., editors, Mesozoic paleogeography of the westcentral United States: Society of Sedimentary Petrology (SEPM), Rocky Mountain Section, Rocky Mountain Paleogeography Symposium 2, p. 253-272.

Schreiber, Edward, Anderson, O.L., and Soga, Naohiro, 1973, Elastic constants and their measurement: McGraw-Hill, New York, 196 p.

Sondergeld, C.H., and Rai, C.S., 1988, Geophysical evaluation module operator's manual: Amoco Research Report T88-E-0033, non-paginated.

1993a, A new concept in quantitative core characterization: The Leading Edge, July, p. 774779. 
1993b, A new exploration tool: quantitative core characterization: PAGEOPH, v. 141, no. 2/3/4, p. 249-268. 


\title{
4. RESERVOIR MODELING
}

\author{
C.B. Forster and S.H. Snelgrove; University of Utah
}

During the project year work focussed on designing and implementing the numerical modeling strategy. This work included developing and testing methodology for generating stochastic permeability fields and modeling subsurface fluid flow. Geostatistical analyses and geological modeling of the local-scale region are essentially complete and preliminary fluid-flow simulations have been performed for both the two- and three-dimensional model domains.

\subsection{Overall Modeling Strategy}

The modeling strategy was finalized following completion of the field-based characterization activities needed to develop input to both geostatistical models and fluid-flow simulators. All modeling work will be focussed on the Kf-1-Iv-a parasequence, the fluvial-dominated deltaic unit exposed at the Ivie Creek case-study area (figure 4.1). Three primary modeling tasks are identified. Tasks I and II involve simulating primary oil production and waterflooding.in two-dimensional model domains containing the clinoform geometries (figure 4.2) characterized in the field activities. In Task III primary oil production and waterflooding will be simulated within three-dimensional model domains containing upscaled renditions of the clinoform geometry.

\subsubsection{Task I - Two-Dimensional Detailed-Scale Simulations}

Task I simulations are aimed at assessing the way that reservoir production practice might be influenced through a better understanding of the detailed variations in permeability and capillary pressures associated with sloping clinoform bounding surfaces. This goal will be accomplished by simulating a set of carefully selected production scenarios in a series of different permeability structures using the most detailed simulation grid possible. In Task I only the properties of the bounding surfaces will be varied in the model domain while maintaining a single petrophysical model for the clinoform interiors. Each simulation sequence will include both primary production and water flood scenarios. Once the sensitivity of the simulation results to variations in bounding surfaces properties is fully assessed, a single permeability structure will be selected and the impact of different infill drilling strategies on production explored. The effectiveness of using the project homogenization method to upscale petrophysical properties in reservoirs containing clinoform geometries will be illustrated by comparing the fine-grid simulation results to those obtained using the homogenization method.

A single, generic, model domain that encompasses up to four complete clinoforms in the $\mathrm{Kf}$ 1-Iv-a of the Ivie Creek amphitheatre will be created (figure 4.3). The model domain will be approximately 600 feet $(183 \mathrm{~m})$ long with permeabilities distributed within the domain according to the rules inferred from work on the Ferron outcrop. Permeability and capillary pressure information will be gleaned from test results in the literature. This fine-grid model (for example, 1 foot by 0.2 foot $[0.3 \times 0.06 \mathrm{~m}]$ grid block) is required to directly assess how capillary pressure effects might influence fluid flow across the bounding surfaces. 


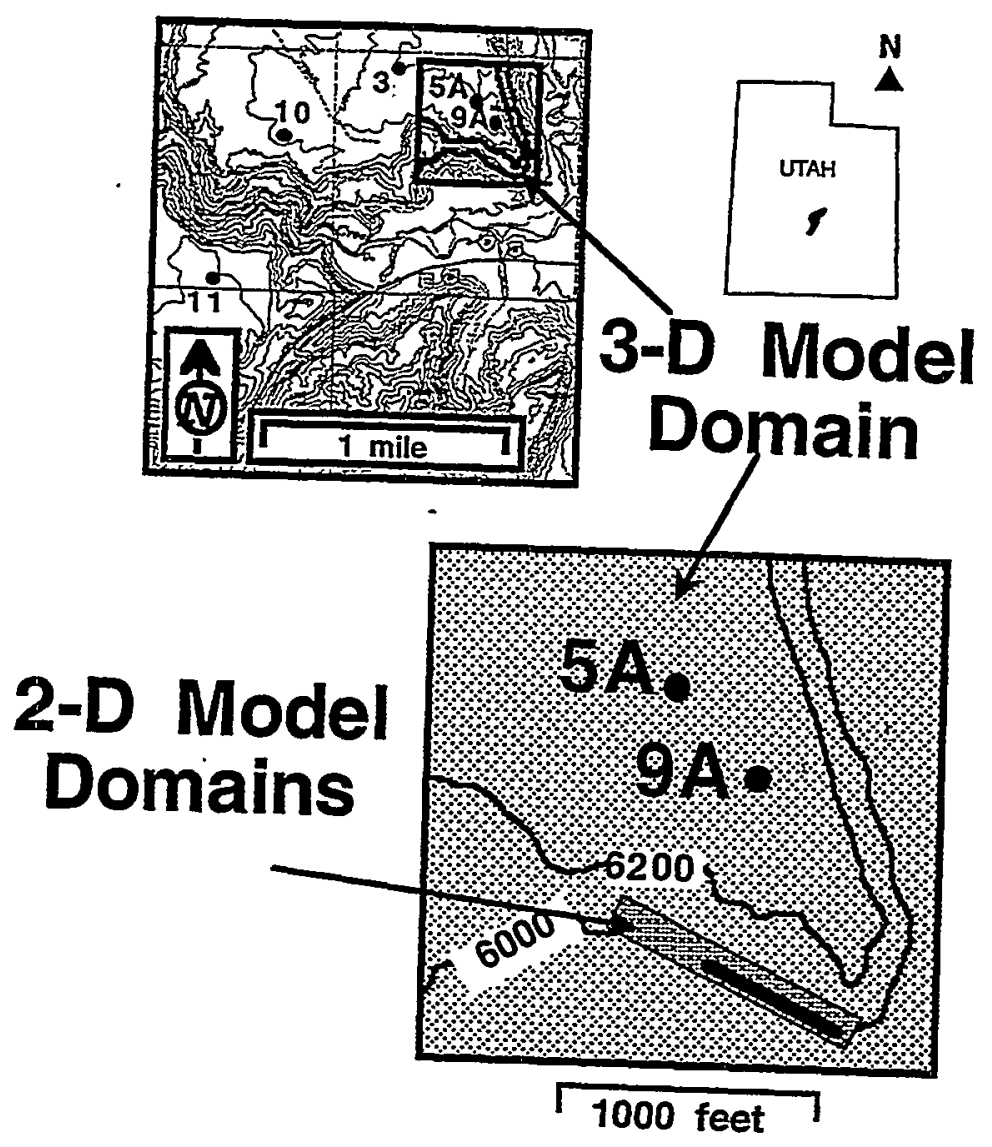

Figure 4.1. Ivie Creek case-study area including location of the two- and three-dimensional model domains to be simulated. The approximate geometry of the intermediate-scale, twodimensional domain is shaded and the detailed two-dimensional domain is a solid black line. Solid dots with associated numbers are locations of project drill holes.

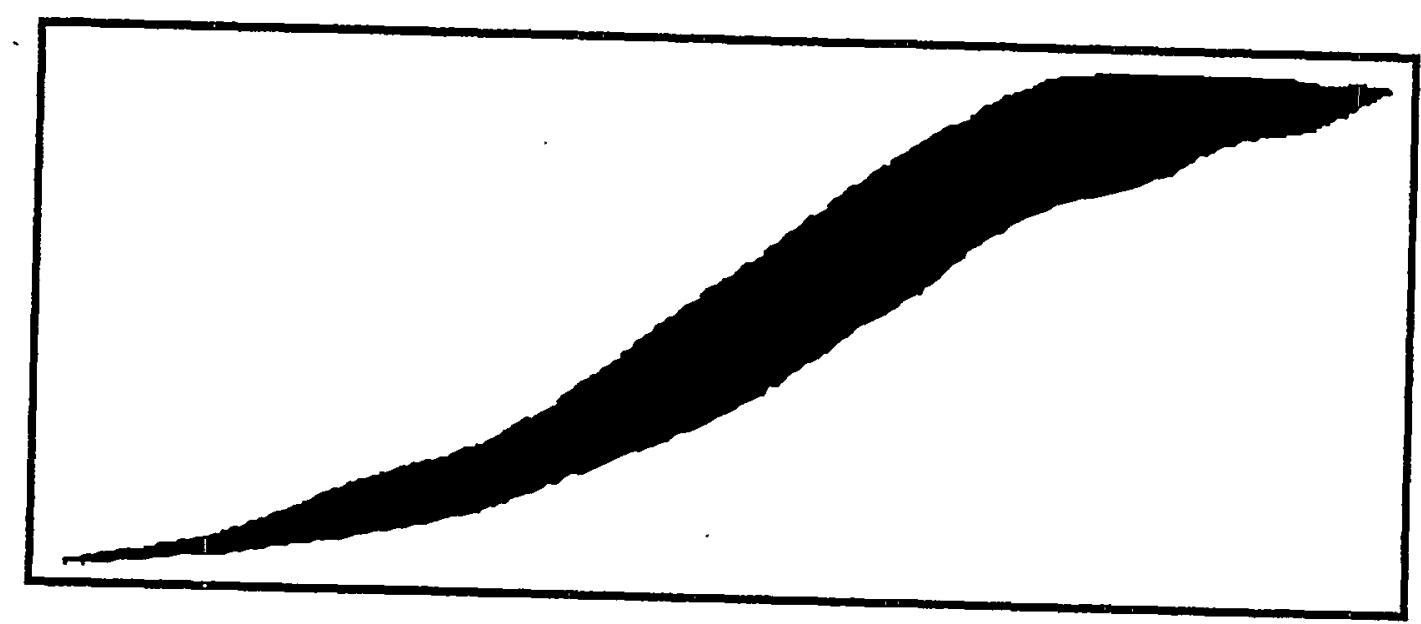

Figure 4.2. Sketch of an idealized clinoform geometry similar to those mapped within the Kf1-Iv-a parasequence on cliffs found at the Ivie Creek case-study area. 


\section{(A)}

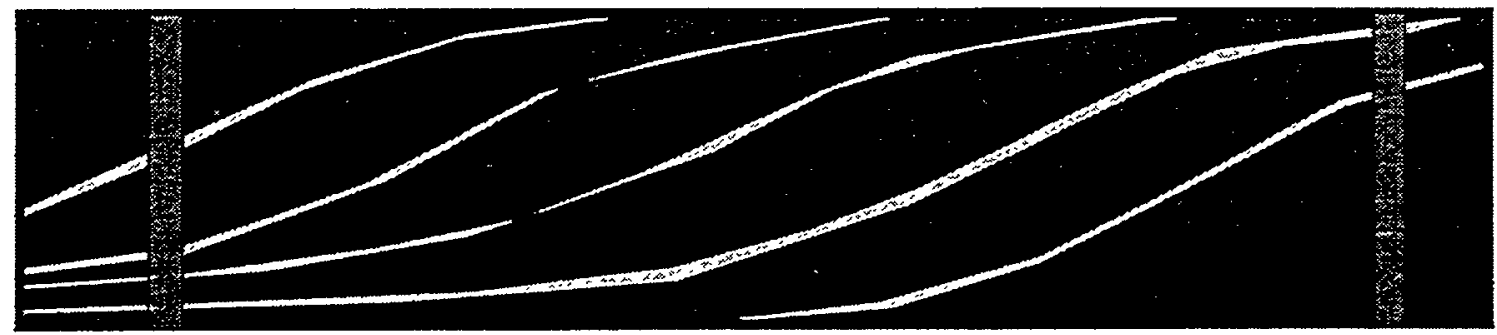

(B)

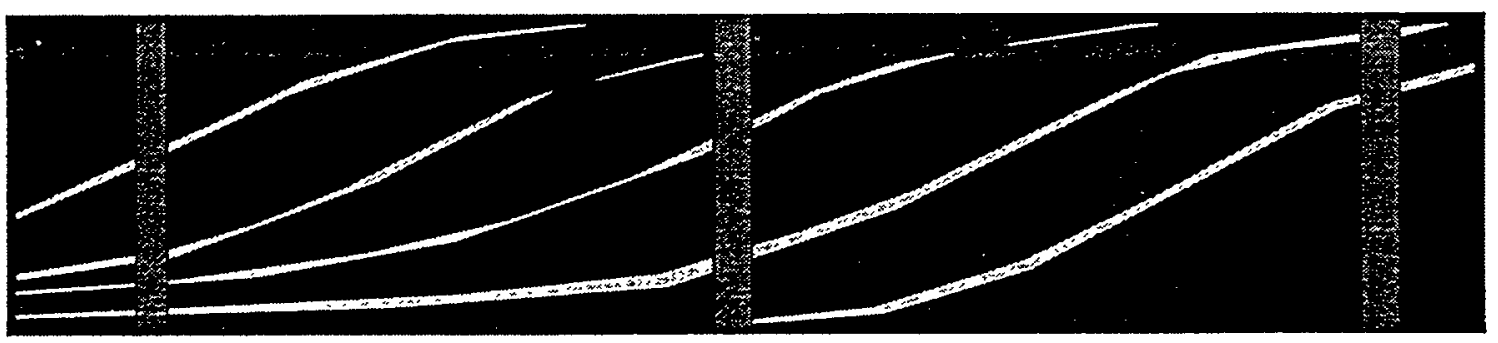

(C)

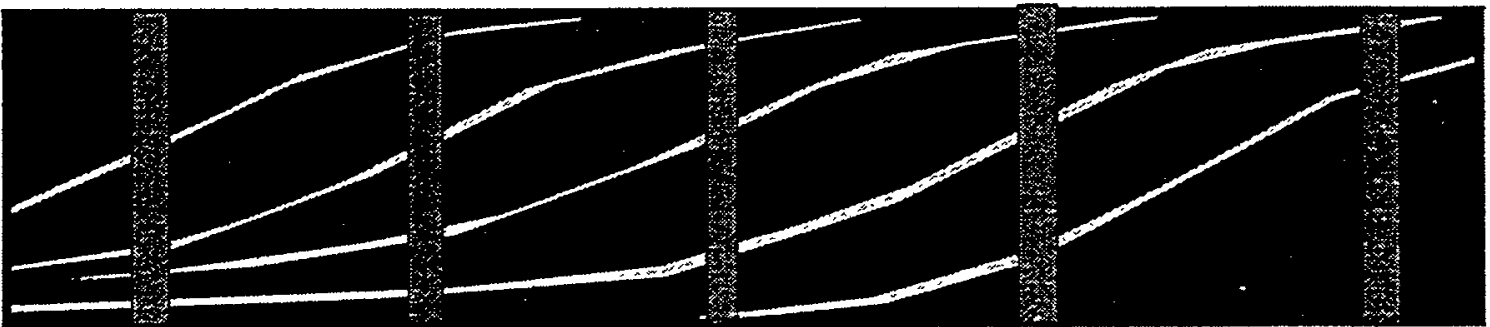

Clinoform Bodies

Bounding Layers Wells

Figure 4.3. Sketch of the most detailed two-dimensional modeling domain showing a generic package of clinoforms with intervening bounding layers for a series of well configurations: (A) wells are isolated if bounding layers are impermeable, (B) well pairs communicate within a single clinoform, and $(C)$ several wells communicate within a single clinoform.

A sensitivity study will be used to explore the way that permeability variations, associated with the sloping bounding surfaces included in the model domain, might influence production strategies using the well configuration of figure $4.3 \mathrm{~A}$. Field-based constraints will be provided by additional detailed mapping, core plugging, and mini-permeameter testing to be carried out next 
quarter. Different permeability distributions will be assigned to the bounding surfaces to determine how they influence reservoir production. Although most of the simulations will use a five-point differencing scheme, the relative merits of using a nine-point differencing scheme in simulating the sloping clinoform geometry will also be assessed.

Once the impact of different bounding surface types has been fully assessed, a simulation study will be done to explore the cost effectiveness of adding infill wells to enhance reservoir production (figures $4.3 \mathrm{~B}$ and $4.3 \mathrm{C}$ ). Although simulation results will be specific to the $\mathrm{Kf}-1-\mathrm{IV}-\mathrm{a}$ outcrop, relationships will be developed that will help to estimate optimal well spacing in other geological environments where clinoform features are found with similar bounding surface geometries and petrophysical properties.

\subsubsection{Task II - Two-Dimensional Intermediate-Scale Simulations}

Task II differs from Task I in two important ways. First, the project studies will be expanded to assess more than just the possible impact of the bounding surfaces on reservoir production. This will be accomplished by developing a single, stochastic petrophysical model that includes variations in the petrophysical properties found within individual clinoforms. The stochastic model will be constrained by the detailed data collected at the Ivie Creek case-study site. Second, a larger gridblock size will be required (for example, 5 feet by 1 foot $[1.5 \times 0.3 \mathrm{~m}]$ ) because of working with a larger model domain (perhaps about 1,000 feet [305 m] long). As before, however, both primary production and water-flood scenarios will be simulated and the effectiveness of the homogenization method will be explored.

The petrophysical model to be simulated is based on the detailed clinoform/lithofacies maps constructed from photomosaics and geological mapping combined with the outcrop-based permeability data. In particular the focus will be on the medial-to-proximal lithofacies exposed in the cliff face at the Ivie Creek amphitheater (figure 4.4). The petrophysical model will include spatially varying permeability and porosity within both the bounding surfaces and the clinoform features. A stochastic approach has been developed to make the petrophysical assignments. A series of reservoir simulations will be run from primary production through water flood for different completion scenarios and infill strategies.

\subsubsection{Task II - Three-Dimensional Reservoir Characterization and Simulation}

The three-dimensional simulations of Task III will provide an opportunity to evaluate how the three-dimensional geometry of facies containing clinoform features might influence full-scale reservoir production. Although the two-dimensional model domains used in Tasks I and II will provide direct insight into the way that detailed variations in petrophysical properties might influence production, the impact of the three-dimensional geometry of clinoform sets cannot be assessed without using a full three-dimensional petrophysical model. Working in three dimensions, however, necessitates working with a larger grid block size ( 20 feet by 20 feet by 4 feet [ $6 \times 6 \times 1.2$ $\mathrm{m}]$ ) in a representative model domain 2,000 feet $(610 \mathrm{~m})$ on a side. A single, carefully-selected production scenario (including both primary production and water flood) will be simulated using three different petrophysical models based on data collected for the Kf-1-Iv-a parasequence at the 


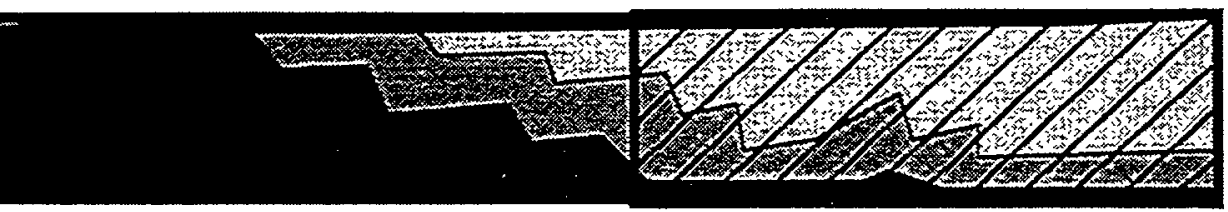

(B) 1 Injector and 1 Producer

圆 Proximal
圆 Medial
Distal
Cap

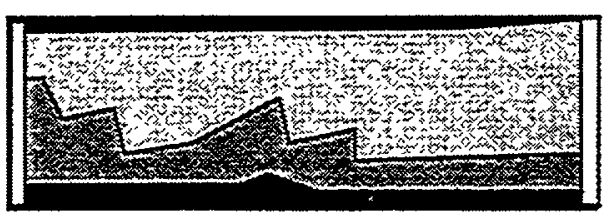

1 injector and 1 Producer
with infill injector/producer

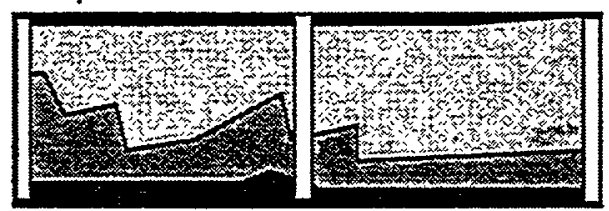

Figure 4.4. Cross section of the intermediate-scale, two-dimensional modeling domain: (A) Kf1-Iv-a parasequence as seen looking north at the cliff face with cut-out (hachured area) indicating medial-to-proximal facies within model, (B) well configuration for two-well production scenario, and (C) well configuration for three-well production scenario.

Ivie Creek amphitheatre; a homogeneous case (figure 4.5A), a simple layered case (figure 4.5B), and a more realistic heterogeneous case (figure $4.5 \mathrm{C}$ ).

The most realistic petrophysical model is based on the gridded three-dimension facies model developed for a 2,000 feet by 2,000 feet $(610 \times 610 \mathrm{~m})$ region of the $\mathrm{Kf}-1-\mathrm{IV}-\mathrm{a}$ at the Ivie Creek amphitheatre. Each petrophysical model used in the Task III simulations will be derived from the permeability and porosity values assigned to each facies type found within the gridded petrophysical domain. Thus, the homogeneous case will be parameterized using bulk averages of the permeability and porosity values assigned in the fully heterogeneous case. The simple layered case will be created using the values of permeability and porosity assigned in the full heterogeneous case at each of the production/injection wells to be included in the simulation. For example, once the synthetic wells are sampled from the three-dimensional petrophysical model, a series of layers containing lateral variations in petrophysical properties will be constructed while ignoring the potential implications of the sloping facies boundaries represented at the case-study site.

Task III will provide a basis for comparing the fluid-flow simulation results obtained using three different representations of the $\mathrm{Kf}-1-\mathrm{IV}$-a petrophysical model. These results will help assess the value of using the three-dimensional geometry of clinoform features in predictive reservoir simulations. 

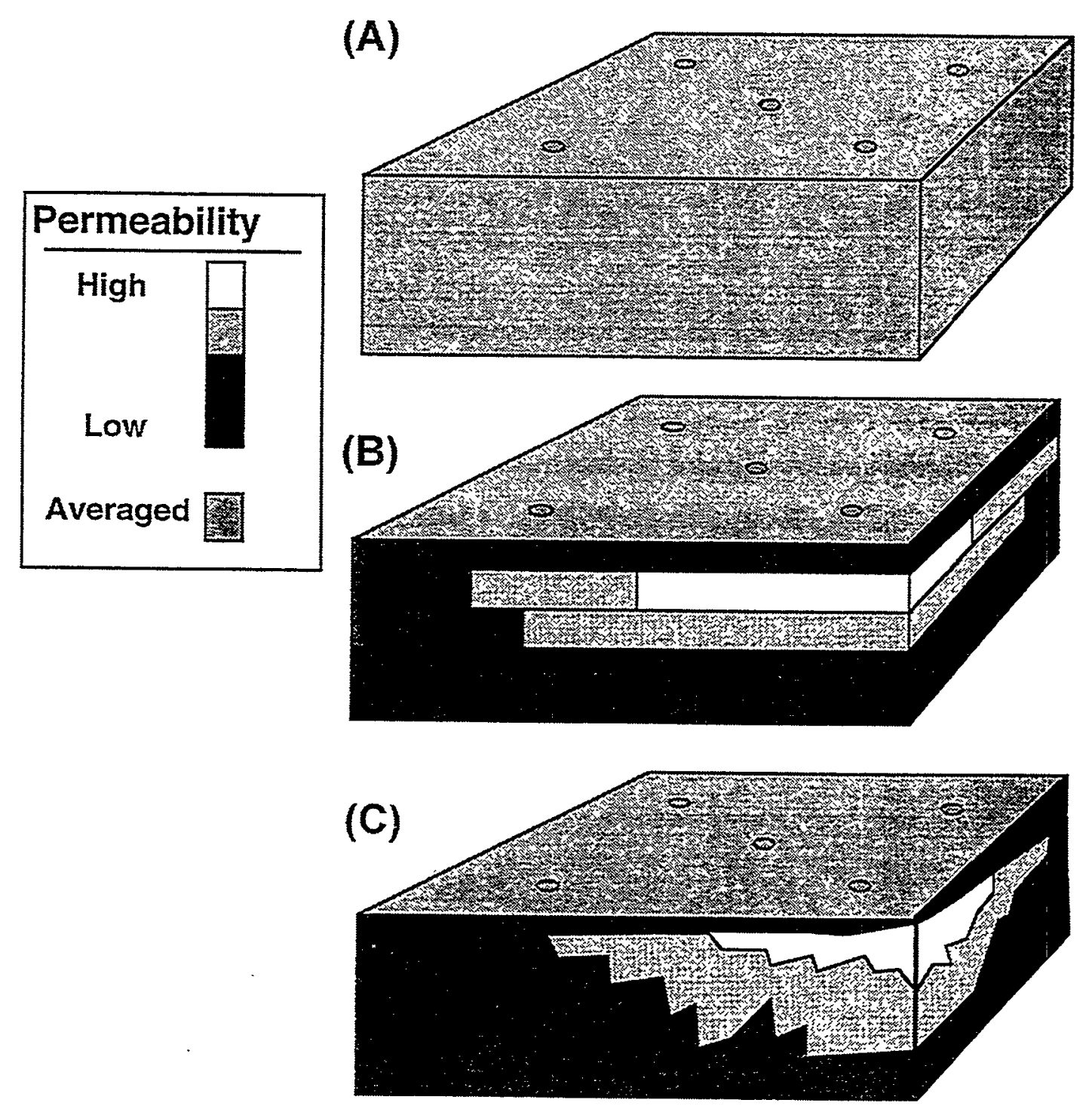

Figure 4.5. Sketch of the three-dimensional model domain showing: (A) homogeneous petrophysical model, (B) simple-layered model, and (C) full heterogeneous model. A hypothetical well pattern is shown on the top surface.

\subsection{Current Status of the Modeling Effort}

During the quarter, clinoform geometries of the Kf-1-Iv-a parasequence were incorporated in both two-dimensional and three-dimensional gridded model domains. In addition, the deterministic and stochastic routines needed to distribute permeability and porosity within the 
clinoform-based model domains have been developed and tested. Preliminary two- and threedimensional fluid-flow simulations also demonstrate that the simulation tasks outlined are ready to proceed. It is anticipated that work performed during the coming quarter will yield significant progress towards completing these modeling tasks.

A key objective of the Ferron Sandstone project flow simulation studies is to incorporate outcrop-based geology and petrophysical properties into the flow models. The extent to which this can be done depends on the relative spatial scales of the flow model, the geological mapping, and the petrophysical data. If the flow modeling is done at a scale much smaller than that of the geological mapping then it is difficult to constrain the flow model using outcrop-derived architecture. Where flow modeling is done at a scale much larger than that of the geological and petrophysical data, averaged data are used. For example, a large flow model may be based on the spatial distribution of facies, each having specific petrophysical properties, rather than representing the more detailed depositional architecture.

\subsubsection{Two-Dimensional Simulations (Tasks I and $\mathrm{m}$ )}

The two-dimensional flow simulations of the Ivie Creek amphitheater are done at a spatial scale near the scale of the outcrop mapping, and somewhat larger than the vertical spacing of outcrop permeability measurements. Because the scales of the data and the flow simulations are so closely matched, the Ivie Creek case-study area provides an uncommon opportunity to examine how the architecture of delta-front deposits influences the spatial distribution of petrophysical properties and hence multiphase fluid flow in the subsurface.

Developing tools for integrating outcrop architecture into flow-simulation models was the focus of the year's activity. Several steps were required to convert the digitized line drawings of architecture provided by the project geologists into a grid that is used both to distribute petrophysical properties and for flow modeling. These include (in chronological order): (1) resolving gaps in the linework, (2) converting the linework to polygons, that is closed regions in space, (3) gridding polygonal regions to enable distribution of properties within individual polygons, and (4) merging individual polygons, with distributed properties, into a flow- simulation model (TETRAD-3D).

The basic architectural element of the Ivie Creek delta-front deposits is the clinoform (figure 4.2), a roughly sigmoidal shape representing an episode of deposition (and thus of delta-front progradation). At the distal end a clinoform laps onto previously deposited sediments (often older clinoforms). Proximally, a clinoform is truncated by a either a younger clinoform or a parasequence boundary. Clinoforms are, therefore, closed regions of space. However, the linework obtained from the geologists included many clinoforms that were not completely enclosed. Lines often ended dangling in space, without terminating against another boundary (figure 4.6A). This was usually due to digitizing, although in some cases it was a result of geological uncertainty about the extent of a clinoform and its relationship to its neighbors. Digitizing problems were resolved manually by extending the line(s) enclosing a clinoform until it terminated against another clinoform, a parasequence boundary, or extended beyond the Ivie Creek case-study area (figure 4.6B). Geological uncertainties were resolved in consultation with project geologists. These linework boundaries were used to define clinoforms as unique polygons (in proper spatial positions) which could then be modeled as individual objects. 
(A)

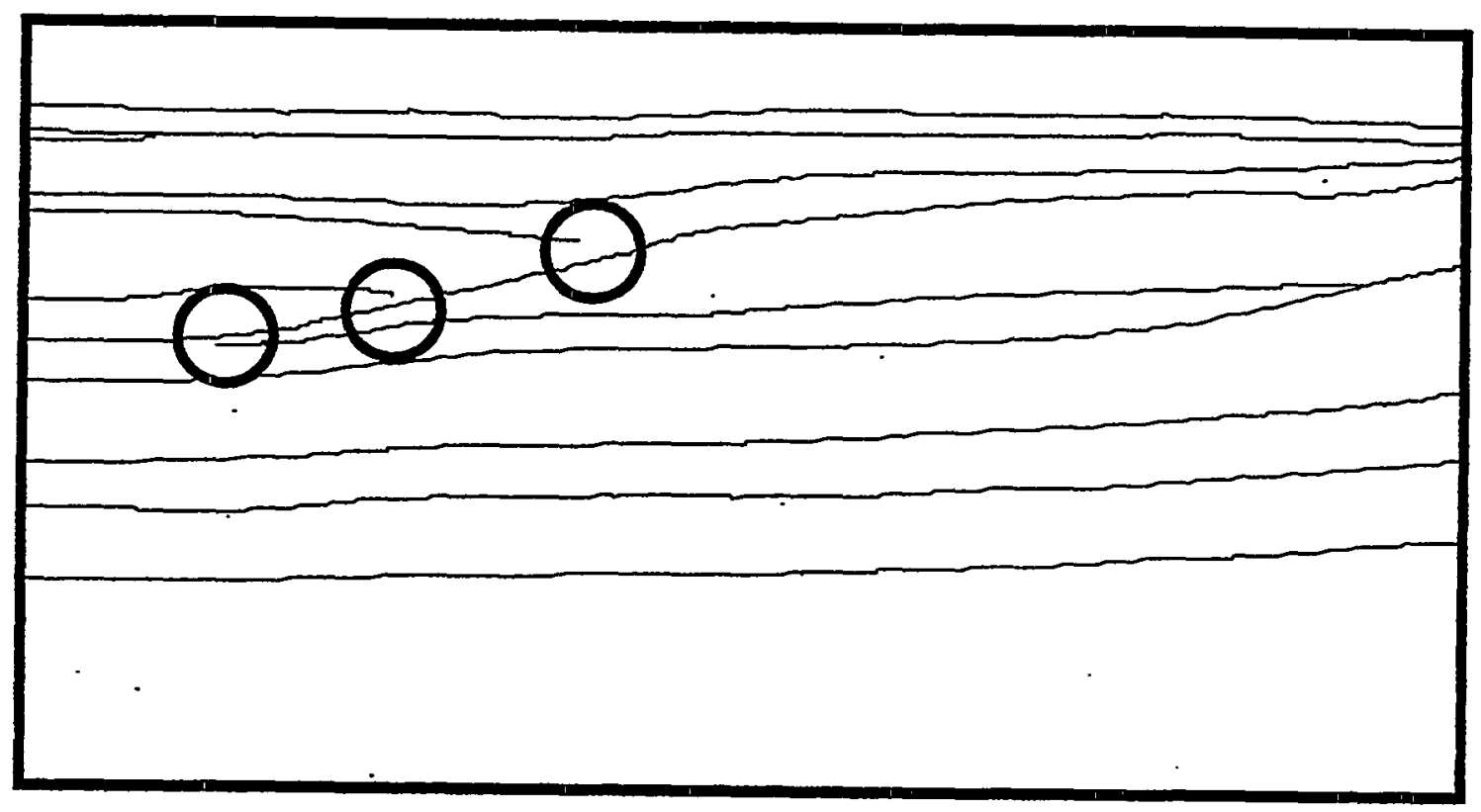

(B)

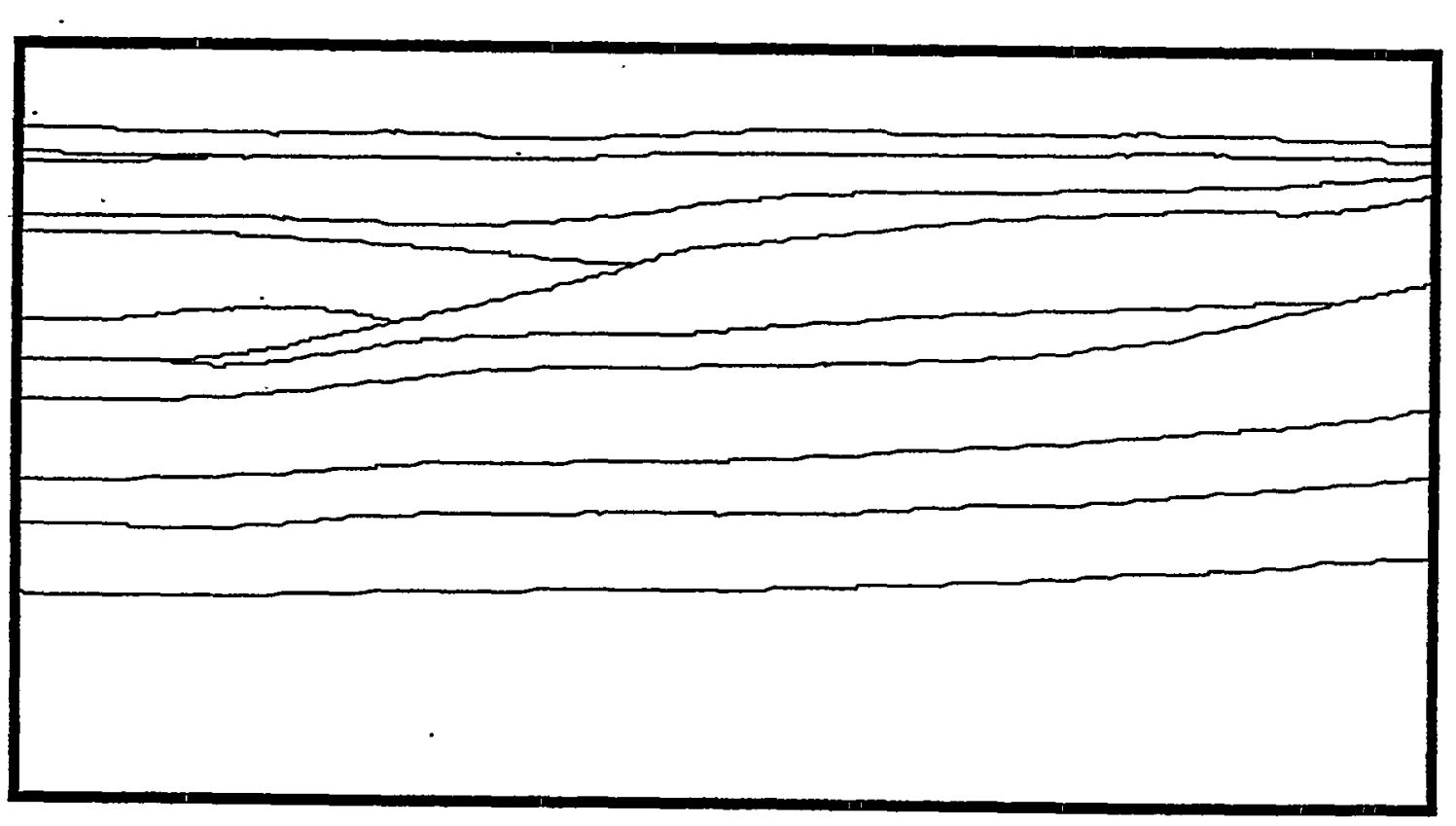

Figure 4.6. Detailed view (not to scale) of some of the clinoforms mapped in the Kf-1-Iv-a parasequence at the Ivie Creek amphitheatre with: (A) gaps between lines marking clinoform boundaries shown by circles, and (B) closed polygons with each clinoform represented as a single closed form. 
Once the boundaries of each clinoform are defined, the clinoform must be gridded in order to assign petrophysical properties in the fluid-flow simulator. Petrophysical properties are then assigned to each grid block in the interior of a clinoform using a deterministic or stochastic approach. Figure $4.7 \mathrm{~B}$ illustrates a gridded version of the clinoforms shown in figure $4.7 \mathrm{~A}$ with the black grid blocks representing thin regions where the properties of bounding surfaces are specifically represented. Two computer programs were written to accomplish these tasks. The gridding program was designed to allow different gridding increments in the $\mathrm{x}$ and $\mathrm{z}$ directions.

(A)

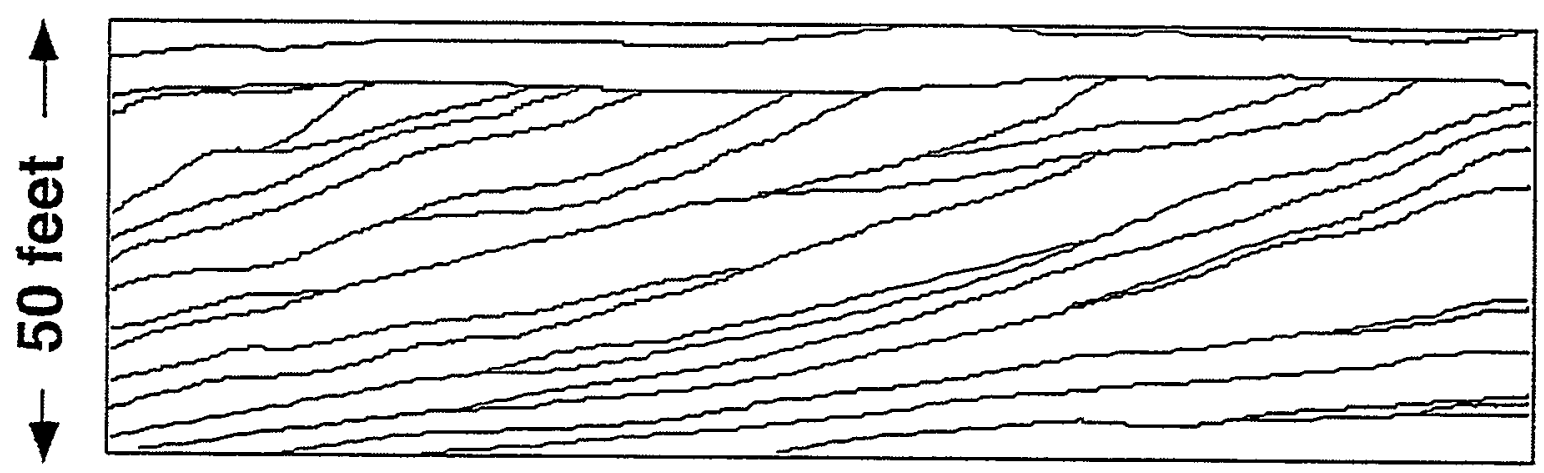

(B)

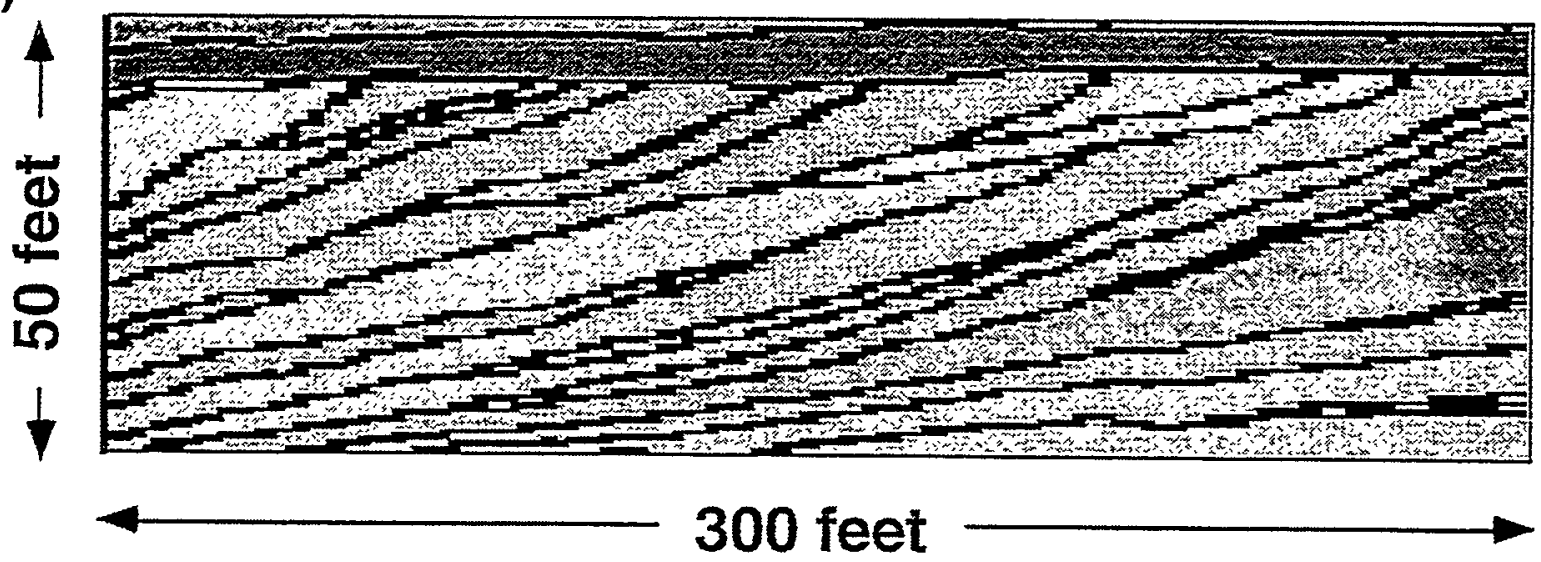

Figure 4.7. Sample model domain showing: (A) closed polygons representing individual clinoforms and (B) digitized polygon set with bounding surfaces represented as black grid blocks having finite height and width.

Each computer program has been tested numerous times. The codes have been used to create a simple test model of a portion of the Ivie Creek amphitheater for preliminary flow simulations. A few flow simulations have now been run, but the results have not been closely examined and so 
are not presented here. The main effort during the final year of the project will be in two areas: (1) populating clinoforms with petrophysical properties, and (2) performing and analyzing flow simulations.

\subsubsection{Three-Dimensional Simulations (Task III)}

The detailed three-dimensional petrophysical model needed to study the Kf-1-Iv-a parasequence at the Ivie Creek amphitheatre was completed during the project year. Although the grid block size ( 20 feet by 20 feet by 4 feet [ $6 \times 6 \times 1.2 \mathrm{~m}]$ thick) is much larger than those used in the two-dimensional simulations, it is still much smaller than what might be used in typical reservoir simulation studies. This block size was selected to provide insight into the way that lumped clinoform geometries might influence the interwell sweep efficiency of different oil production strategies. Preliminary three-dimensional simulations have been completed for a simple homogeneous case using TETRAD-3D. Full-scale simulations of both the homogeneous and heterogeneous petrophysical models are ready to begin.

\subsubsection{Continuing Effort to Create Synthetic Clinoform-Like Objects}

Chidsey and Allison (1996) have outlined the planned use of a stochastic code to generate packages of stacked clinoform-like objects that resemble the features mapped in the Kf-1-Iv-a parasequence at the Ivie Creek amphitheatre. The modeled result is being improved by integrating a new set of "soft" rules based on geological inferences. This is an empirical approach where the algorithm will be modified to produce new versions of the clinoform packages that more closely approximate the geometry of the clinoform packages mapped in outcrop. Over the past year a series of statistical measures have been developed that characterize the clinoform geometry mapped in the Ivie Creek photomosaics. These statistical measures will be used to constrain models of synthetic clinoform structures then populate the clinoforms with permeability and porosity values following the approach described above in Tasks I and II. The results of two-dimensional fluid-flow simulations performed on model domains containing the synthetic clinoform packages will be compared to simulation results obtained with the deterministic clinoform geometries identified in the field. This approach is expected to provide a basis for creating the synthetic two- and threedimensional clinoform geometries needed to model oil production in reservoir systems where similar geological environments are encountered.

\subsection{Summary}

Now that the field-based information needed to begin the fluid-flow simulation tasks is available, a modeling strategy has been developed and implemented. Algorithms are in place to distribute permeability and porosity within clinoform geometries derived from either: (1) the field-based photomosaics, or (2) the stochastic code. The TETRAD-3D code is being used to perform preliminary fluid-flow simulations with both the two- and three-dimensional petrophysical models. 


\subsection{References}

Chidsey, T.C., Jr., and Allison, M.L., 1996, Geological and petrophysical characterization of the Ferron Sandstone for 3-D Simulation of a fluvial-deltaic reservoir - annual report for the period October 1, 1994 to September 30, 1995: U.S. Department of Energy, DOE/BC/14896$13,104 \mathrm{p}$. 


\section{TECHNOLOGY TRANSFER}

Thomas C. Chidsey, Jr.; Utah Geological Survey

The UGS is the Principal Investigator for three government-industry cooperative.petroleumresearch projects including the Ferron Sandstone project. The projects are designed to improve recovery, development, and exploration of the nation's oil and gas resources through use of better, more efficient technologies. The projects involve detailed geologic and engineering characterization of several complex heterogeneous reservoirs. Two of the projects will include practical oil-field demonstrations of. selected technologies. The U.S. Department of Energy (DOE) and multidisciplinary teams from petroleum companies, petroleum service companies, universities, private consultants, and State agencies are co-funding the three projects.

The UGS will release all products of the Ferron Sandstone project in a series of formal publications. These will include all the data as well as the results and interpretations. Syntheses and highlights will be submitted to referred journals as appropriate, such as the American Association of Petroleum Geologists (AAPG) Bulletin and Journal of Petroleum Technology, and to trade publications such as the Oil and Gas Journal. This information will also be released through the UGS Petroleum News, Survey Notes, and on the project Internet home page.

Project materials, plans, and objectives were displayed at the UGS booth during the 1996 annual national convention of the AAPG in San Diego, California; the 1996 AAPG Rocky Mountain Section annual meeting in Billings, Montana; and at a UGS co-sponsored symposium entitled the Geology and Resources of the Paradox Basin in Durango, Colorado. Three to four UGS scientists staffed the display booth at these events. An abstract was submitted for a technical presentation at the 1997 AAPG national meeting.

The UGS began preparing to present the final results of the project to both academia and industry. Field trips covering the regional stratigraphy and case-study areas will be conducted during the 1997 Geological Society of America (GSA) and 1998 AAPG annual national meetings. The field trip road logs and Ferron interpretations will be published in a two-volume GSA guidebook. A UGS co-sponsored short course presenting reservoir modeling and simulation results will also be offered during the AAPG meeting. The meetings will be held in Salt Lake City, Utah, October 1922, 1997 (GSA) and May 20-23, 1998 (AAPG).

During this project year, technology transfer activity for the Ferron Sandstone project has continued to yield an additional benefit. The Ferron Sandstone has become the dominant coalbed methane play in Utah (figure 5.1). Databases, strip logs, and maps produced from the project have been used by numerous operators exploring and developing this new resource. Based on data generated in this project we estimate the play will support 3,400 wells, nearly doubling the total number of producing wells in Utah. Total potential reserves of coalbed methane in the Ferron "fairway" range from 4 to 9 trillion cubic feet of gas. The UGS released Ferron total coal, depth to top, and vitrinite reflectance maps in an open-file report. 


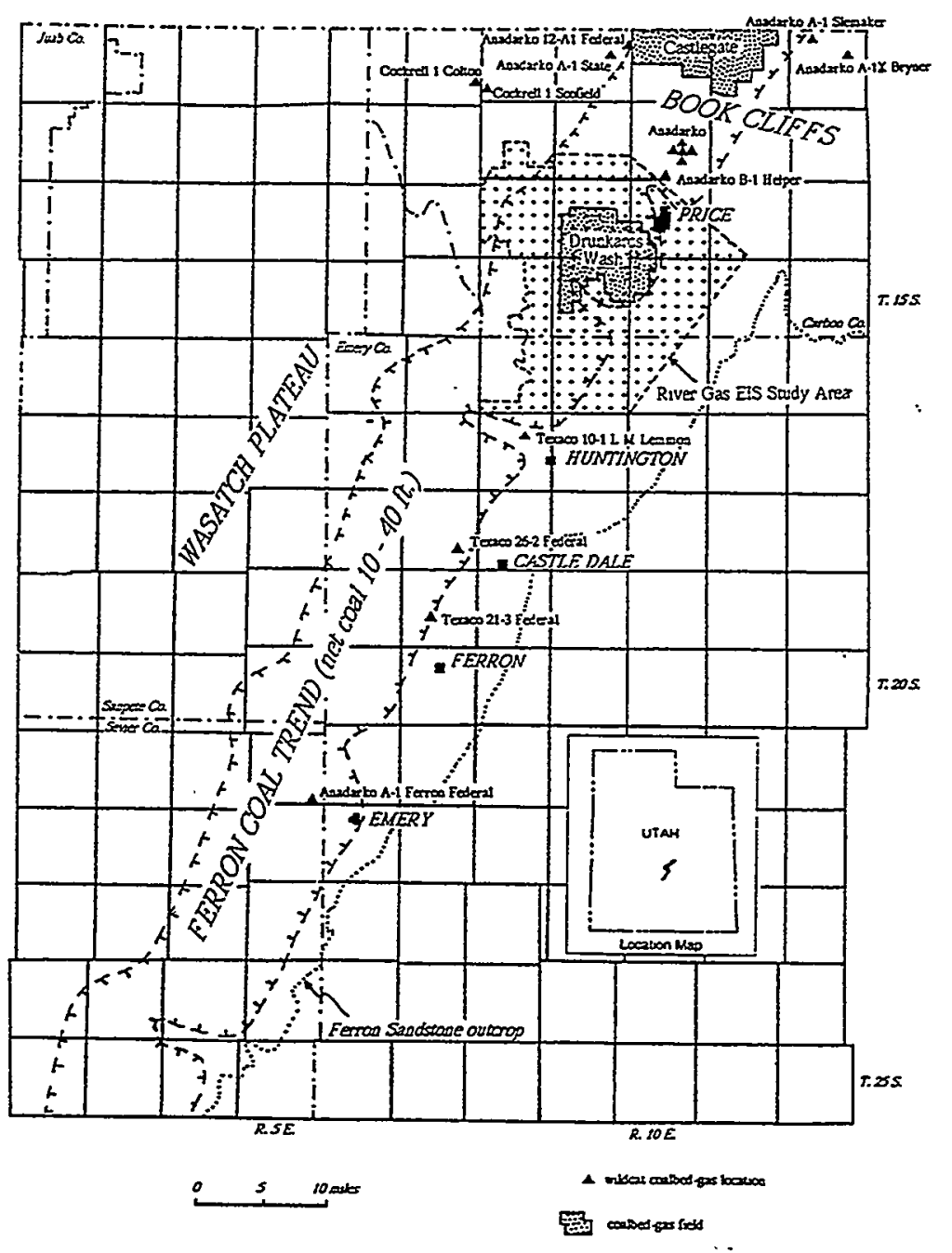

Figure 5.1. Location of the Ferron coalbed gas "fairway" (labeled Ferron Coal Trend), Drunkards Wash field, and drilling prospects, Carbon, Emery, Sanpete, and Sevier Counties, Utah.

\subsection{Utah Geological Survey Petroleum News, Survey Notes, and Internet Web Site}

The purpose of the UGS Petroleum News newsletter is to keep petroleum companies, researchers, and other parties involved in exploring and developing Utah energy resources, informed of the progress on various energy-related UGS projects. The UGS Petroleum News contains articles on: (1) DOE-funded and other UGS petroleum project activities, progress, and results, (2) current drilling activity in Utah including coalbed methane, (3) new acquisitions of well cuttings, core, and crude oil at the UGS Sample Library, and (4) new UGS petroleum publications. The purpose of 
Survey Notes is to provide nontechnical information on contemporary geologic topics, issues, events, and ongoing UGS projects to Utah's geologic community, educators, state and local officials and other decision makers, and the public. Survey Notes is published three times yearly and Petroleum News is published semi-annually. Single copies are distributed free of charge and reproduction (with recognition of source) is encouraged.

The UGS established a web site on the Internet, http://www.ugs.state.ut.us. This site includes a page under the heading Economic Geology Program, which describes the UGS/DOE cooperative studies (Ferron Sandstone, Paradox basin, and Bluebell field), contains the latest issue of Petroleum News, and has a link to the U.S. Department of Energy web site. Each UGS/DOE cooperative study also. has its own separate page on the UGS web site. The Ferron Sandstone project page (http://www.ugs.state.ut.us/ferron1.htm) contains: (1) a project location map, (2) a description of the project, (3) a list of project participants and their postal addresses and phone numbers, (4) executive summaries from the first and second annual reports, (5) each of the project Quarterly Technical Progress reports, (5) descriptions of Ferron Sandstone parasequences, (6) a reference list of all publications that are a direct result of the project, and (7) a listing of Ferron publications available at the UGS.

\subsection{Presentations}

The following technical and nontechnical presentations were made during the year as part of the Ferron Sandstone project technology transfer activities. These presentations described the Ferron project in general and gave detailed information on the coalbed methane play, sequence stratigraphy, geostatistics, and reservoir models.

"Geology and Gas Potential of Utah's Ferron Sandstone" by M.L. Allison, Guest Lecturer; Association of Petroleum \& Mining Landmen, Salt Lake City, Utah, January 1996.

"Geology and Development Activity of the Ferron Sandstone Coalbed Methane Fairway" by D.E. Tabet; public information meeting, Emery County Courthouse at the request of the Emery County Planning Commission, Castle Dale, Utah, March 1996.

"Flow Based Scale-Up of Heterogeneous Porous Media using Homogenization and Wavelet Representation" by Joe Koebbe; Second International Symposium on Spatial Accuracy Assessment in Natural Resources and Environmental Sciences, Colorado State University, Fort Collins, Colorado, May 1996.

"Facies Relationships and Statistical measures for Reservoir Heterogeneities in the Cretaceous Ferron Sandstone, Central Utah" by Ann Mattson and M.A. Chan; American Association of Petroleum Geologists Annual Convention, San Diego, California, May 1996.

"Impact of Lithofacies Architecture and Distribution on Fluid Flow: Examples from the Cretaceous Ferron Sandstone, East-Central Utah" by S.H. Snelgrove, C.B. Forster, Ann 
Mattson, and M.A. Chan; American Association of Petroleum Geologists Annual Convention, San Diego, California, May 1996.

"Geology of the Ferron Sandstone Coalbed Methane "Fairway," Central Utah" by D.E. Tabet, B.P. Hucka, and S.N. Sommer; American Association of Petroleum Geologists Annual Convention, San Diego, California, May 1996.

"Ferron Sandstone - Stratigraphy and Reservoir Analogs, East-Central Utah" by P.B. Anderson, T.A. Ryer, and T.C. Chidsey, Jr., American Association of Petroleum Geologists Rocky Mountain Section Meeting, Billings, Montana, July 1996.

"Geological and Petrophysical Characterization of Ferron Sandstone for Simulation of a Fluvial Deltaic Reservoir” by T.C. Chidsey, Jr., Guest Speaker; Reservoir Description NOE Shared Learning Symposium, Denver, Colorado, August 1996.

Project team members were the recipients of two major awards for presentations made during the 1995 AAPG Rocky Mountain Section meeting held in Reno, Nevada. The A.I. Levorson Award for best paper went to T.A. Ryer and P.B. Anderson for their paper entitled "Parasequence Sets, Parasequences, Facies Distributions, and Depositional History of the Upper Cretaceous Ferron Deltaic Clastic Wedge, Utah." The Runge Award for best student paper went to J.A. Dewey, Jr., T.H. Morris, and T.A. Ryer for their paper entitled "Constraining Reservoir Models of Fluvial- vs. Wave-Dominated Delta-Front Sandstones through High Resolution and High Density Sequence Stratigraphic Analysis, Ferron Sandstone, Utah."

\subsection{Publications}

Anderson, P.B., Ryer, T.A., and Chidsey, T.C., Jr., 1996, Ferron Sandstone - stratigraphy and reservoir analogs, east-central Utah [abs.]: American Association of Petroleum Geologists Bulletin, v. 80 , no. 6 , p. 965.

Bon, R.L., 1996, UGS tech-transfer activities are in full swing at recent petroleum industry meeting: Utah Geological Survey, Survey Notes, v. 28, no. 1, p. 8.

Chidsey, T.C., Jr., and Allison, M.L., 1996, Geological and petrophysical characterization of the Ferron Sandstone for 3-D Simulation of a fluvial-deltaic reservoir - annual report for the period October 1, 1994 to September 30, 1995: U.S. Department of Energy, DOE/BC/14896$13,104 \mathrm{p}$.

Hucka, B.P., Sommer, S.N., Sprinkel, D.A., and Tabet, D.E., 1995, Ferron Sandstone drill-hole strip logs, Ferron Creek to Last Chance Creek, Emery and Sevier Counties, Utah: Utah Geological Survey Open-File Report 331, 1417 p., 2 volumes. 
Mattson, Ann, and Chan, M.A., 1996, Facies relationships and statistical measures for reservoir heterogeneities in the Cretaceous Ferron Sandstone, central Utah [abs.]: American Association of Petroleum Geologist Annual Convention, Program with Abstracts, p. A93.

Snelgrove, S.H., Forster, C.B., Mattson, Ann, and Chan, M.A., 1996, Impact of lithofacies architecture and distribution on fluid flow: examples from the Cretaceous Ferron Sandstone, east-central Utah [abs.]: American Association of Petroleum Geologist Annual Convention, Program with Abstracts, p. A132.

Tabet, D.E., Hucka, B.P., and Sommer, S.N., 1995, Maps of total Ferron coal, depth to the top, and vitrinite reflectance for the Ferron Sandstone Member of the Mancos Shale, central Utah: Utah Geological Survey Open-File Report 329, 3 plates, scale 1:250,000.

Tabet, D.E., Hucka, B.P., and Sommer, S.N., 1996, Geology of the Ferron Sandstone coalbed methane "fairway," central Utah [abs.]: American Association of Petroleum Geologist Annual Convention, Program with Abstracts, p. A137.

Tabet, D.E., and Burns, Terry, 1996, Drunkards Wash, in Hill, B.G., and Bereskin, S.R., editors, Oil and gas fields of Utah: Utah Geological Association Publication 22 (Addendum): unpaginated.

Utah Geological Survey, 1996, Ferron sandstone project moves to reservoir simulation stage: Utah Geological Survey, Petroleum News (May), p. 2-4.

U.S. Department of Energy, 1995, Geological and petrophysical characterization of the Ferron Sandstone for 3-D simulation of a fluvial-deltaic reservoir, in Contracts for field projects and supporting research on enhanced oil recovery, reporting period July-September 1994: Progress Review No. 80, DOE/BC--94/4, p. 40-45.

U.S. Department of Energy, 1996, Geological and petrophysical characterization of the Ferron Sandstone for 3-D simulation of a fluvial-deltaic reservoir, in Contracts for field projects and supporting research on enhanced oil recovery, reporting period October-December 1994: Progress Review No. 81, DOE/BC--95/1, p. 112-118.

U.S. Department of Energy, 1996, Geological and petrophysical characterization of the Ferron Sandstone for 3-D simulation of a fluvial-deltaic reservoir, in Contracts for field projects and supporting research on enhanced oil recovery, reporting period January-March 1995: Progress Review No. 82, DOE/BC--95/2, p. 66-73.

U.S. Department of Energy, 1996, Geological and petrophysical characterization of the Ferron Sandstone for 3-D simulation of a fluvial-deltaic reservoir, in Contracts for field projects and supporting research on enhanced oil recovery, reporting period April-June 1995: Progress Review No. 83, DOE/BC--95/3, p. 77-81. 